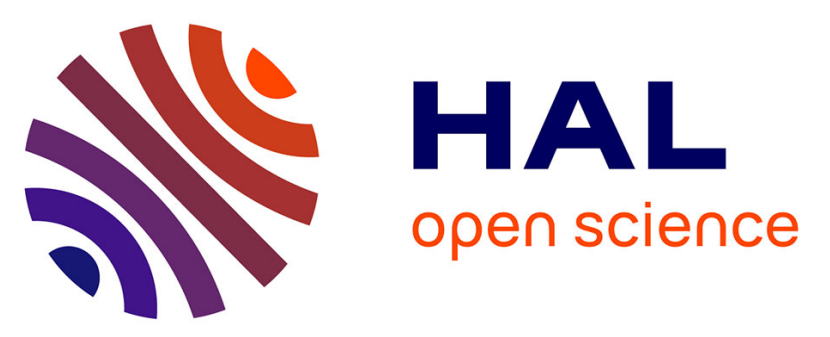

\title{
High-Throughput Screening of the Alkoxide/Oxime-Based Library An Alternative to Organotin Compounds for the Alkoxysilane Condensation in Adhesives and Sealants
}

B. Colin, Olivier Lavastre, S. Fouquay, G. Michaud, F. Simon, J.-M. Brusson

\section{To cite this version:}

B. Colin, Olivier Lavastre, S. Fouquay, G. Michaud, F. Simon, et al.. High-Throughput Screening of the Alkoxide/Oxime-Based Library An Alternative to Organotin Compounds for the Alkoxysilane Condensation in Adhesives and Sealants. ACS Combinatorial Science, 2019, 21 (4), pp.300-309. 10.1021/acscombsci.8b00161 . hal-02050595

HAL Id: hal-02050595

https://hal-univ-rennes1.archives-ouvertes.fr/hal-02050595

Submitted on 13 Mar 2019

HAL is a multi-disciplinary open access archive for the deposit and dissemination of scientific research documents, whether they are published or not. The documents may come from teaching and research institutions in France or abroad, or from public or private research centers.
L'archive ouverte pluridisciplinaire HAL, est destinée au dépôt et à la diffusion de documents scientifiques de niveau recherche, publiés ou non, émanant des établissements d'enseignement et de recherche français ou étrangers, des laboratoires publics ou privés. 


\title{
High-throughput screening of alkoxide/oxime-based
}

\section{library: an alternative to organotin compounds for the alkoxysilane condensation in adhesives and sealants}

Boris Colin ${ }^{\dagger *}$, Olivier Lavastre ${ }^{\ddagger}$, Stéphane Fouquay ${ }^{\dagger}$, Guillaume Michaud ${ }^{\dagger}$, Frédéric Simon ${ }^{\dagger}$ and Jean-Michel Brusson ${ }^{\S}$

† BOSTIK SMART TECHNOLOGY CENTER ZAC du bois de Plaisance 101, rue du Champ Cailloux, 60280 Venette, France

$\$$ Laboratory of Functional Materials, IETR, UMR 6164 CNRS, University of RENNES 1, 263 Avenue du Général Leclerc, 35042 Rennes Cedex, France

$\S$ TOTAL S.A., Tour Michelet A, 24, Cours Michelet, 92069 La Défense Cedex, France *Corresponding author. Tel.: +33 344306114 ; E-mail address: boris.colin@bostik.com

KEYWORDS: silyl-modified polymers, tin-free catalysts, cross-linking, high-throughput screening.

\begin{abstract}
In this work, a high-throughput screening (HTS) method was used to discover new efficient catalysts to substitute organotin compounds (DBTDL) for the cross-linking of silylmodified polymers (SMPs). We report here on the use of our HTS method to investigate a library of alkoxide/oxime systems with different metal/ligand (M/L) ratios. Among the 156 candidates tested, 40 interesting hits were detected. Then, the cross-linking times for the better hits were measured on the SMP. Some of these seem to be more efficient than DBTDL and exhibit a good
\end{abstract}


stability during storage in cartridges. Thereby, a high efficiency of alkoxide/oxime systems was established that shows great potential for the generation of new ligands to provide new tin-free catalysts for the cross-linking of adhesives and sealants.

\section{GRAPHICAL ABSTRACT:}

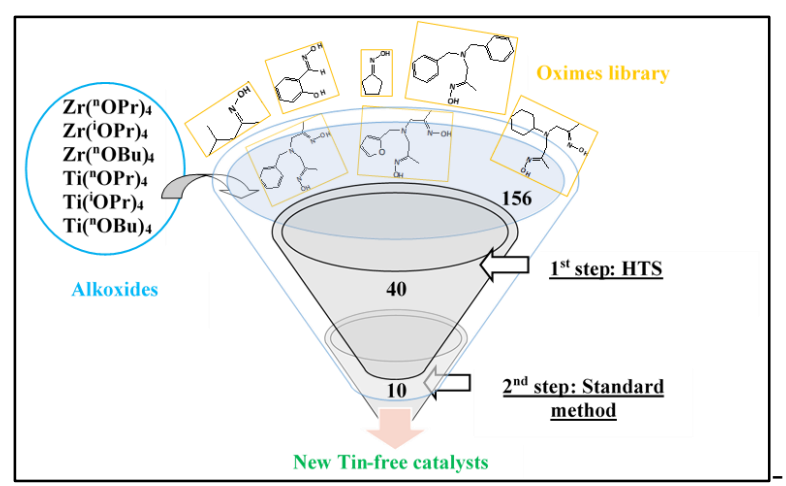




\section{INTRODUCTION}

Silyl-modified polymers (SMPs) are organosilane-based materials containing organic and inorganic moieties that can form polymers with the beneficial characteristics of both parts and without some of their disadvantages. Presently, SMPs are used as key materials in adhesive ${ }^{1}$, sealant $^{2}$ and coating ${ }^{3}$ applications. These hybrid polymers are widely used in the do-it-yourself (DIY) market as adhesives or sealants and are applied to a large variety of indoor and outdoor applications for construction. They can be used in several other specific applications in the food and beverage industry ${ }^{4}$ or as electrolytes ${ }^{5}$. The cross-linking of SMPs occurs with alkoxysilane groups attached to the ends of the polymer chains by hydrolysis and polycondensation with moisture (Fig. 1). Without the addition of any catalyst, the cross-linking of alkoxysilane slowly occurs with moisture. Therefore, a catalysis of both a hydrolysis and condensation reaction is necessary to accelerate the curing time and achieve a fully cross-linked material. Indeed, Brønsted acids, such as $\mathrm{HOTf}^{6}, \rho-\mathrm{TSA}^{7}$ or $\mathrm{HCl}^{8}$, and superbases, such as $\mathrm{DBU}$ and $\mathrm{TBD}^{9}$ or phosphazene ${ }^{10}$, are very efficient at improving the cross-linking time of organosilanes. However, these are usually avoided in sealants as they could result in some side effects, such as a reaction of acids with calcium carbonate-based fillers, odor diffusion from the material, color change over time, or migration of the catalyst from the 3D cross-linked polymer to another matrix in contact with the polymer. As organometallic catalysts have a better compatibility, organotin compounds such as dibutyltin dilaurate (DBTDL) or dioctyltin dilaurate (DOTL) represent the best references to accelerate the cross-linking of SMP with moisture ${ }^{11}$. In this case, the true catalytic species is a dibutyltin laurate hydroxide intermediate. However, in several years, the high toxicity of organotin compounds has been confirmed and new regulatory restrictions on the use of tin catalysts have been enacted. Therefore, there is a great need to find new efficient tin-free catalysts to anticipate stronger restrictions in coming years or the ban of organotin compounds. Some alternatives were 
already used by DOW in silicone chemistry with the use of oxime compounds and titanium catalysts $^{12}$. More recently, titanium and zirconium alkoxides ${ }^{13}$ have been used as tin-free catalysts in sealants containing SMP. This kind of alkoxide has the disadvantage of being unstable with moisture and thus easily hydrolyzed with a longer curing time of the sealant after storage in cartridges. To address this issue, alkoxides can be stabilized with a large variety of chelating agents, such as acetylacetone ${ }^{14}$, acetic acid $^{15}$ or diethanolamine ${ }^{16}$ to form M-O-C bonds.

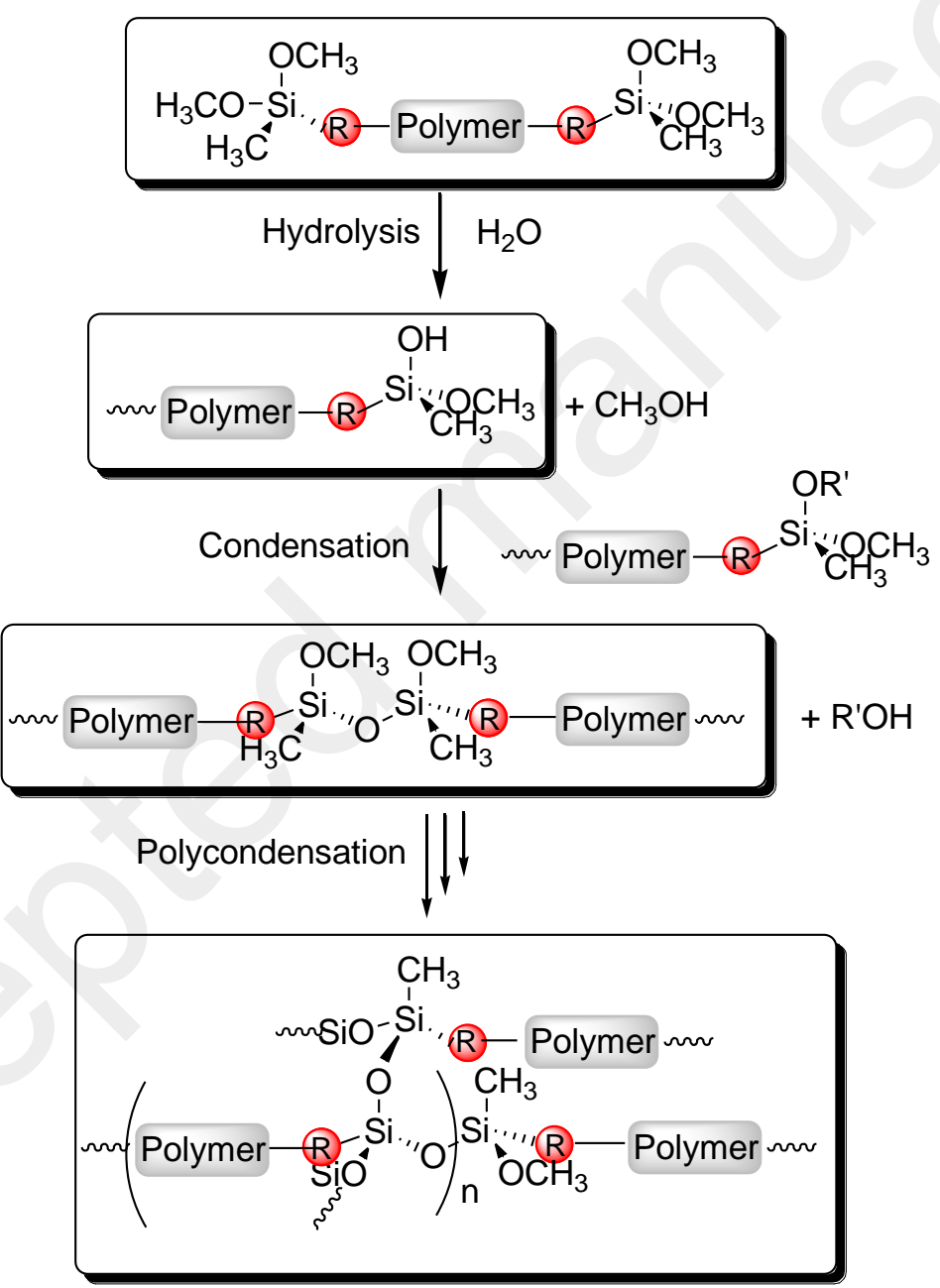

Figure 1. General scheme of hydrolysis and polycondensation reactions $\left(\mathrm{R}=\mathrm{CH}_{2} \mathrm{NHCOO}\right.$ or $\mathrm{C}_{3} \mathrm{H}_{6} \mathrm{O}$ and $\mathrm{R}^{\prime}=\mathrm{H}$ or $\mathrm{CH}_{3}$ ). 
Oxime ligands can also present the potential to modify titanium and zirconium alkoxides to obtain complexes, which are more resistant to air and moisture ${ }^{17}$. To our knowledge, the use of these ligands combined with titanium or zirconium alkoxides to provide $\mathrm{M}-\mathrm{O}-\mathrm{N}$ bonds has not been described for the cross-linking of SMPs in adhesives and sealants. Thereby, a library of N-tripodal dioxime ligands was established from a previous work by our team to form copper-, nickel- and cobalt-based catalysts with dioxime ligands for the copolymerization of ethylene/ $\alpha$-olefins ${ }^{18}$. Several mono-oxime ligands were added to this library (Fig. 2) to compare the effects of di- or mono-oximes and their roles in coordination with alkoxides to cross-link SMPs (Fig. 3) ${ }^{19}$.
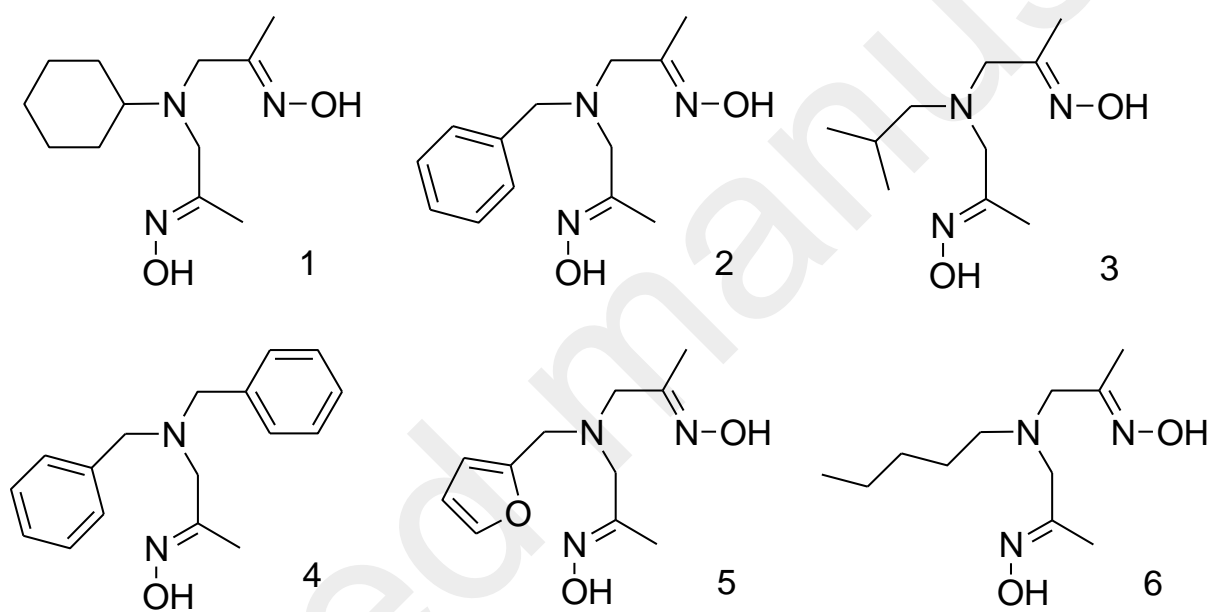

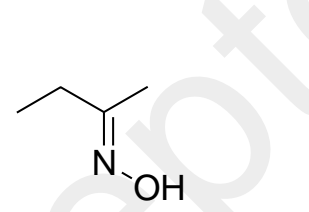

7

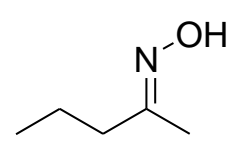

11<smiles>ON=C1CCCCC1</smiles><smiles>ON=C1CCCC1</smiles>

12

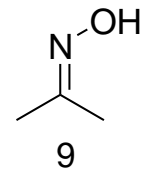

9<smiles>O/N=C/c1ccccc1O</smiles>

13

Figure 2. Library of dioxime and mono-oxime ligands. 

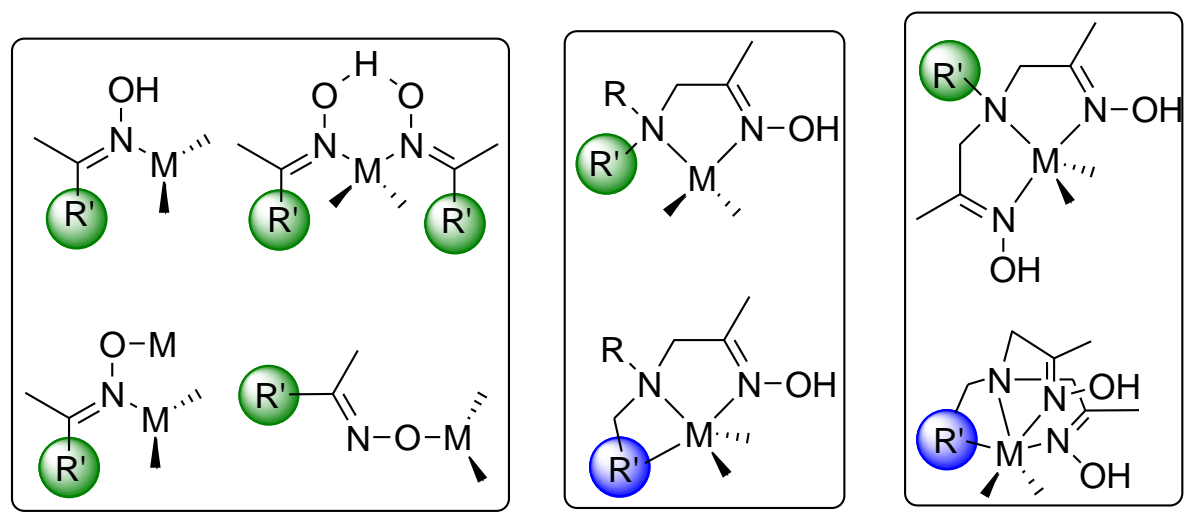
R' = without heteroatom
$\mathrm{R}^{\prime}=$ with heteroatom

Figure 3. Possible mode of coordination by using simple mono-oxime (a), Ntripodal mono-oximes (b) and N-tripodal dioximes (c).

It has already been established that high-throughput screening can play an important role in discovering new efficient catalysts ${ }^{20}$. Therefore, we report here on using our HTS method, which was previously described to detect efficient catalysts for the fast cross-linking of SMPs ${ }^{21}$. This method is based on a multiwell plate containing SMPs and with 96 different catalysts (one per well, Fig. 4a). Then, for a given time, the surface of each well was touched with a 24 multichannel tip system to visualize the physical state (viscous or skin effect, Fig. 4b). Finally, the multichannel tip system is applied to paper sheet to evaluate the cross-linking time. Thus, when the surface is viscous, there is a drop on the tip system, meaning that the catalyst is inefficient (no cross-linking). When a skin effect occurs, there is no drop on the tip system, meaning that the catalyst is efficient (Fig. 4c). This method is applied here to screen a large number of alkoxide/oxime systems over different periods of time and to quickly identify new and efficient catalysts able to replace organotin compounds. 

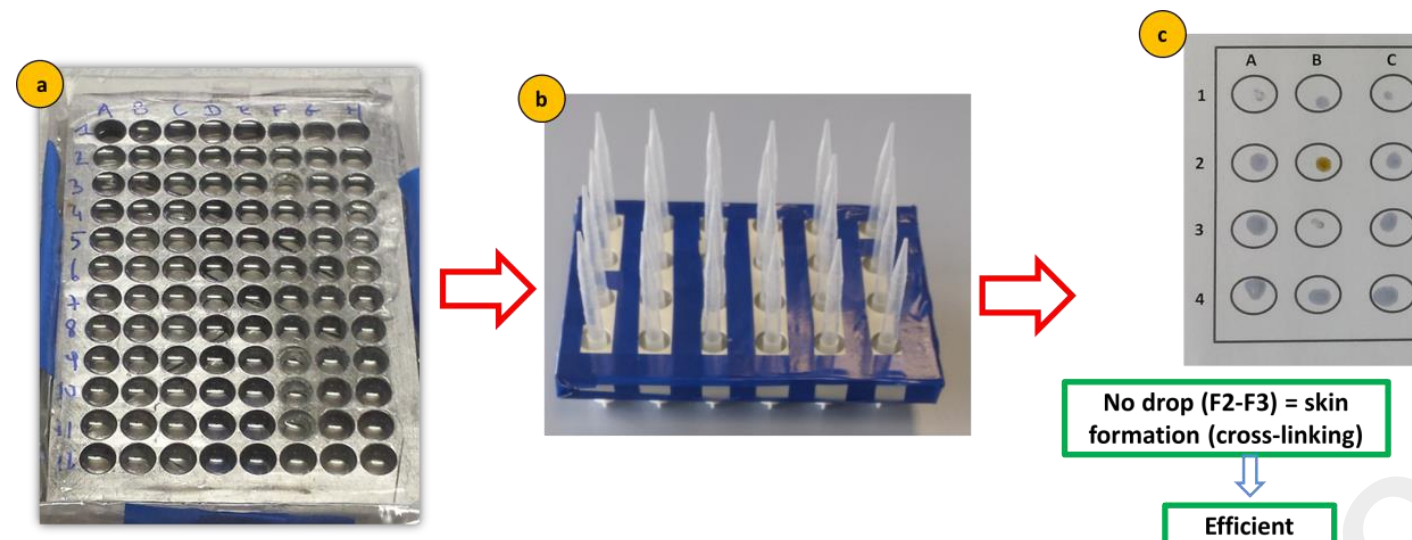

\section{formation (cross-linking)}

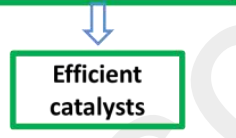

Drop $=$ liquid or viscous prepolymer (no cross-linking)

Figure 4. Scheme of HTS method representing a multiwell plate containing SMP and a maximum of 96 catalysts (a), the 24 multichannel tip system (b) and an example of the results obtained after the screening of 24 catalysts at a given time (c). 


\section{EXPERIMENTAL SECTION}

General data. Commercially available reagents were used without further purification, and solvents were dried by standard procedures. NMR spectra were recorded using a Bruker $300 \mathrm{MHz}$ WB proton Advance I 300 instrument operating at $300 \mathrm{MHz}$ for ${ }^{1} \mathrm{H}$ spectra and $50 \mathrm{MHz}$ for ${ }^{13} \mathrm{C}$ spectra. Mass spectrometry analyses were performed using a JEOL JMS-T100CS (AccuTOF CS) orthogonal time-of-flight (TOF) mass spectrometer (Peabody, MA) equipped with an IonSense DART Source (Danvers, MA). Elemental analyses were performed with a microanalysor Flash EA1112 instrument.

Adhesive materials. The silyl-modified polymer used in this study is named SMP1 and was sent by BOSTIK. This polymer is a dimethoxysilane-terminated polyether (Fig. 5). As a reminder, rates of RTV cure as follow RCOO-Si $>\mathrm{R}-\mathrm{C}=\mathrm{N}-\mathrm{O}-\mathrm{Si}>\mathrm{RO}-\mathrm{Si}$ meaning that the reactivity of the alkoxysilanes used in the current study is low.

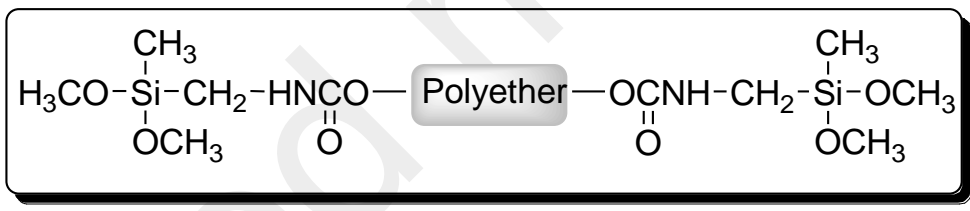

Figure 5. Structure of SMP1.

Chemical products. Hydroxylamine hydrochloride $\left(\mathrm{NH}_{2} \mathrm{OH} . \mathrm{HCl}, 99 \%\right)$, Chloroacetone $(95 \%)$, Potassium carbonate $\left(\mathrm{K}_{2} \mathrm{CO}_{3}, \geq 99 \%\right.$ ), Sodium hydroxide (pellets, $\geq 97 \%$ ), Triethylamine (TEA, >99\%), Cyclohexylamine (99\%), Benzylamine (99\%), Isobutylamine (99\%), Dibenzylamine (97\%), Furfurylamine ( $\geq 99 \%)$, Amylamine ( $\geq 99 \%)$, Cyclohexanone oxime (97\%), Acetone oxime (98\%), 2-Butanone oxime (99\%), Metal-based catalysts: Dibutyltin dilaurate (DBTDL, 95\%wt), Zirconium(IV) propoxide $\left(\mathrm{Zr}(\mathrm{IV})^{\mathrm{n}} \mathrm{OPr}, 70 \% \mathrm{wt}\right)$, Zirconium(IV) isopropoxide $\left(\mathrm{Zr}(\mathrm{IV})^{\mathrm{i}} \mathrm{OPr}\right.$, 99,9\%wt), Zirconium(IV) butoxide ( $\mathrm{Zr}(\mathrm{IV})^{\mathrm{n}} \mathrm{OBu}, 80 \% \mathrm{wt}$ ), Titanium(IV) propoxide (Ti(IV) ${ }^{\mathrm{n}} \mathrm{OPr}$, 98\%wt), Titanium(IV) isopropoxide (Ti(IV) ${ }^{\mathrm{i}} \mathrm{OPr}, 97 \% \mathrm{wt}$ ), Titanium(IV) butoxide (Ti(IV) ${ }^{\mathrm{n}} \mathrm{OBu}$, 
97\%wt), Solvents: Tetrahydrofuran ( $\geq 99 \%)$, Ethyl ether ( $\geq 99 \%)$, Acetonitrile ( $\geq 99,5 \%)$ and Ethyl acetate $(\geq 99,5 \%)$ were purchased from Sigma Aldrich and used without further purification. Synthesis of Triethylamine Adduct of Chloroacetone Oxime (TACO reagent) ${ }^{22}$. Hydroxylamine hydrochloride (182 mmol, $12.65 \mathrm{~g})$ is dissolved in distilled water $(80 \mathrm{~mL})$ and a solution of chloroacetone $(165.4 \mathrm{mmol}, 13.63 \mathrm{~mL})$ in ethyl ether $(200 \mathrm{~mL})$ is added. The mixture is cooled to $0^{\circ} \mathrm{C}$ and potassium carbonate $(91 \mathrm{mmol}, 12.57 \mathrm{~g}$ ) is slowly added under stirring (magnetic stir bar), leading to a gas release. After 2 hours, the layers are separated and the aqueous phase is extracted with ethyl ether $(60 \mathrm{~mL})$. Triethylamine $(172 \mathrm{mmol}, 24 \mathrm{~mL})$ diluted in acetonitrile $(60 \mathrm{~mL})$ is added dropwise onto the organic phase and the mixture is stirred for 30 minutes to obtain a white precipitate. The solid is filtered and washed with cold acetonitrile (120 $\mathrm{mL}$ ). A second precipitation can occur in the filtrate, which is in that case filtered and the solid is also washed with cold acetonitrile $(3 \times 40 \mathrm{~mL})$. The combined solids are dried under vacuum during 1 night to provide TACO (34.42 g, 99,7\%) as a white powder. ${ }^{1} \mathrm{H}$ NMR (300 MHz, DMSO- $\left.d_{6}\right) \delta$ : $11.81(\mathrm{~s}, 1 \mathrm{H}), 4.05(\mathrm{~s}, 2 \mathrm{H}), 3.29(\mathrm{~m}, 6 \mathrm{H}), 1.95(\mathrm{~s}, 3 \mathrm{H}), 1.24$ (t, J=6.7Hz, 9H); ${ }^{13} \mathrm{C}$ NMR $(50 \mathrm{MHz}$ DMSO- $\left.d_{6}\right) \delta: 147.58,59.43,53.31,15.76,7.86$. Anal. Calcd C, 51.79; H, 10.14; N, 13.42. Found: C, 52.05; H, 10.23; N, 13.71 .

General procedure for the preparation of oxime ligands $\underline{1}$ to $\underline{6}^{23}$. Commercially available primary or secondary amine $(6 \mathrm{mmol})$ is added into a flask. TACO reagent (from 6.6 to 13.2 mmol) and acetonitrile $(80 \mathrm{~mL})$ are successively added and the mixture is stirred (magnetic stir bar), at $85^{\circ} \mathrm{C}$ during 6 hours. After cooling, acetonitrile is evaporated and ethyl acetate is added $(30 \mathrm{~mL})$ to precipitate residual TACO and formed ammonium salt. The mixture is filtered and washed with ethyl acetate $(2 \times 14 \mathrm{~mL})$. The combined organic layers are evaporated to provide the oxime ligand $\underline{\mathbf{1}}$ to $\underline{\mathbf{6}}$. 
Ligand 1: 1-[Cyclohexyl-(2-hydroxyimino-propyl)-amino]-propan-2-one oxime (91\%); ${ }^{1} \mathrm{H}$ NMR $\left(300 \mathrm{MHz}, \mathrm{CDCl}_{3}\right) \delta: 8.97(\mathrm{~s}, 2 \mathrm{H}), 3.14(\mathrm{~s}, 4 \mathrm{H}), 2.45(\mathrm{~m}, 1 \mathrm{H}), 1.89(\mathrm{~s}, 6 \mathrm{H}), 1.81(\mathrm{~m}, 4 \mathrm{H}), 1.62(\mathrm{~m}$, 1H), 1.28-1.19 (m, 5H); ${ }^{13} \mathrm{C} \mathrm{NMR}\left(50 \mathrm{MHz}, \mathrm{CDCl}_{3}\right) \delta: 157.51,60.02,54.19,28.59,26.21,26.02$, 12.11. MS found for $\left[\mathrm{M}+\mathrm{H}^{+}\right]=242.18133$. Anal. Calcd C, 59.72; H, 9.61; N, 17.41. Found: $\mathrm{C}$, 59.32; H, 9.67; N, 17.15.

Ligand 2: 1-[Benzyl-(2-hydroxyimino-propyl)-amino]-propan-2-one oxime $(80 \%)$; ${ }^{1} \mathrm{H}$ NMR $\left(300 \mathrm{MHz}, \mathrm{CDCl}_{3}\right) \delta: 9.16(\mathrm{~s}, 2 \mathrm{H}), 7.34-7.27(\mathrm{~m}, 5 \mathrm{H}), 3.53(\mathrm{~s}, 2 \mathrm{H}), 3.06(\mathrm{~s}, 4 \mathrm{H}), 1.92(\mathrm{~s}, 6 \mathrm{H}) ;{ }^{13} \mathrm{C}$ NMR $\left(50 \mathrm{MHz}, \mathrm{CDCl}_{3}\right) \delta: 156.89,129.04,128.35,127.24,58.50,57.68,12.45 . \mathrm{MS}$ found for $\left[\mathrm{M}+\mathrm{H}^{+}\right]=250.16327$. Anal. Calcd C, 62.63; H, 7.68; N, 16.85. Found: C, 62.34; H, 7.62; N, 17.09. Ligand 3: 1-[isobutyl-(2-hydroxyimino-propyl)-amino]-propan-2-one oxime (84\%); ${ }^{1} \mathrm{H}$ NMR $\left(300 \mathrm{MHz}, \mathrm{CDCl}_{3}\right) \delta: 8,28(\mathrm{~s}, 2 \mathrm{H}), 3.14-3.03(\mathrm{~m}, 4 \mathrm{H}), 2.17(\mathrm{~m}, 2 \mathrm{H}), 2.05(\mathrm{~m}, 1 \mathrm{H}), 1.93(\mathrm{~s}, 6 \mathrm{H})$, $0.89(\mathrm{~m}, 6 \mathrm{H}) ;{ }^{13} \mathrm{C} \mathrm{NMR}\left(50 \mathrm{MHz}, \mathrm{CDCl}_{3}\right) \delta: 157.17,62.92,58.73,26.22,20.68,12.44$. MS found for $\left[\mathrm{M}+\mathrm{H}^{+}\right]=216.15743$. Anal. Calcd C, 55.79; H, 9.83; N, 19.52. Found: C, 55.57; H, 9.75; N, 19.69.

Ligand 4: 1-[Dibenzyl-(2-hydroxyimino-propyl)-amino]-propan-2-one oxime (92\%); ${ }^{1} \mathrm{H}$ NMR $\left(300 \mathrm{MHz} \mathrm{CDCl}_{3}\right) \delta: 8.53(\mathrm{~s}, 1 \mathrm{H}), 7.41-7.27(\mathrm{~m}, 10 \mathrm{H}), 3.60(\mathrm{~m}, 4 \mathrm{H}), 3.10(\mathrm{~s}, 2 \mathrm{H}), 1.95(\mathrm{~s}, 3 \mathrm{H})$; ${ }^{13} \mathrm{C} \mathrm{NMR}\left(50 \mathrm{MHz}, \mathrm{CDCl}_{3}\right) \delta: 139.02,128.92,128.34,127.16,58.11,57.54,12.31 . \mathrm{MS}$ found for $\left[\mathrm{M}+\mathrm{H}^{+}\right]=269.17766$. Anal. Calcd C, 76.09; H, 7.51; N, 10.44. Found: C, 75.53; H, 7.57; N, 10.55 .

Ligand 5: 1-[Furanyl-(2-hydroxyimino-propyl)-amino]-propan-2-one oxime (98\%); ${ }^{1} \mathrm{H}$ NMR $\left(300 \mathrm{MHz}, \mathrm{CDCl}_{3}\right) \delta: 9.09(\mathrm{~s}, 2 \mathrm{H}), 7.79-7.39(\mathrm{~m}, 3 \mathrm{H}), 3.58(\mathrm{~m}, 2 \mathrm{H}), 3.12(\mathrm{~s}, 4 \mathrm{H}), 1.92(\mathrm{~s}, 6 \mathrm{H}) ;{ }^{13} \mathrm{C}$ NMR (50 MHz, $\left.\mathrm{CDCl}_{3}\right) \delta: 154.31,152.17,142.9,110.77,109.41,57.36,49.21,12.47$. MS found 
for $\left[\mathrm{M}+\mathrm{H}^{+}\right]=240.14754$. Anal. Calcd C, 55.22; H, 7.16; N, 17.56. Found: C, 55.07; H, 7.15; N, 17.29.

Ligand ㅇ: 1-[amyl-(2-hydroxyimino-propyl)-amino]-propan-2-one oxime (89\%); ${ }^{1} \mathrm{H}$ NMR $\left(300 \mathrm{MHz}, \mathrm{CDCl}_{3}\right) \delta: 8.07(\mathrm{~s}, 2 \mathrm{H}), 3.96(\mathrm{~s}, 1 \mathrm{H}), 3.64(\mathrm{~m}, 8 \mathrm{H}), 3.12(\mathrm{~s}, 4 \mathrm{H}), 2.03(\mathrm{~s}, 2 \mathrm{H}), 1.93(\mathrm{~s}$, $6 \mathrm{H}) ;{ }^{13} \mathrm{C} \mathrm{NMR}\left(50 \mathrm{MHz}, \mathrm{CDCl}_{3}\right) \delta: 130.48,129.32,129.07,128.95,128.42,57.99,48.98,12.36$. MS found for $\left[\mathrm{M}+\mathrm{H}^{+}\right]=230.18952$. Anal. Calcd C, 57.61; H, 10.11; N, 18.32. Found: C, 55.46; H, 10.05; N, 17.37.

General procedure for the preparation of oxime ligands with ketone $\underline{10}$ to $\underline{13}^{24}$ : Sodium hydroxide (100 mmol, $4 \mathrm{~g})$ is dissolved in distilled water $(10 \mathrm{~mL})$ and a solution of ketone $(80$ $\mathrm{mmol}$ ) is added. The mixture is cooled to $0^{\circ} \mathrm{C}$ and a solution of hydroxylamine hydrochloride (100 mmol, $6.95 \mathrm{~g})$ in distilled water $(12 \mathrm{~mL})$ is slowly added under stirring (magnetic stir bar). After 1 night, the layers are separated and the organic phase is washed with distilled water $(2 \times 20 \mathrm{~mL})$. Water residues are evaporated and the organic layer is dried under vacuum during 1 night to provide ketoxime ligand $\underline{\mathbf{1 0}}$ to $\underline{\mathbf{1 3}}$.

Ligand 10: Methylisobutylketoxime (96\%); ${ }^{1} \mathrm{H}$ NMR $\left(300 \mathrm{MHz}, \mathrm{CDCl}_{3}\right) \delta: 8.68(\mathrm{~s}, 1 \mathrm{H}), 2.08(\mathrm{~s}$, 2H), 1.95-1.88 (m, 4H), 0.94 (s, 3H), $\left.0.92(\mathrm{~s}, 3 \mathrm{H}) ;{ }^{13} \mathrm{C} \mathrm{NMR} \mathrm{(50} \mathrm{MHz,} \mathrm{CDCl}_{3}\right)$ \&: 158.11, 44.70, 25.83, 22.34, 13.54. MS found for $[\mathrm{M}+\mathrm{H}]^{+}$116.1012. Anal. Calcd C, 62.57; H, 11.38; N, 12.16. Found: $\mathrm{C}, 61.88 ; \mathrm{H}, 11.19 ; \mathrm{N}, 11.78$.

Ligand 11: 2-Pentanone oxime (94\%); ${ }^{1} \mathrm{H}$ NMR (300 MHz, $\left.\mathrm{CDCl}_{3}\right) \delta: 8.87(\mathrm{~s}, 1 \mathrm{H}), 2.37$ (m, 2H), 1.90 (s, 3H), $1.57(\mathrm{~m}, 2 \mathrm{H}), 0.94(\mathrm{~m}, 3 \mathrm{H}) ;{ }^{13} \mathrm{C} \mathrm{NMR}\left(50 \mathrm{MHz}, \mathrm{CDCl}_{3}\right) \delta: 158.58,37.71,19.76$, 19.55, 13.61. MS found for $[\mathrm{M}+\mathrm{H}]^{+}$102.0589. Anal. Calcd C, 59.37; H, 10.96; N, 13.85. Found: C, 58.39; H, 10.41; N, 13.36 . 
Ligand 12: Cyclopentanone oxime (85\%); ${ }^{1} \mathrm{H}$ NMR $\left(300 \mathrm{MHz}, \mathrm{CDCl}_{3}\right) \delta: 7.18(\mathrm{~s}, 1 \mathrm{H}), 2.48(\mathrm{~m}$, 2H), $2.38(\mathrm{~m}, 2 \mathrm{H}), 1.77(\mathrm{~m}, 4 \mathrm{H}) ;{ }^{13} \mathrm{C} \mathrm{NMR}\left(50 \mathrm{MHz}, \mathrm{CDCl}_{3}\right) \delta: 167.56,30.85,27.16,25.18,24.56$. MS found for $[\mathrm{M}+\mathrm{H}]^{+}$100.0408. Anal. Calcd C, 60.58; H, 9.15; N, 14.13. Found: C, 59.86; H, 8.99; N, 13.80 .

Ligand 13: Salicylaldoxime (91\%); ${ }^{1} \mathrm{H}$ NMR (300 MHz, $\left.\mathrm{CDCl}_{3}\right) \delta: 9.74(\mathrm{~s}, 1 \mathrm{H}), 8.17$ (s, 1H), 7.21 $(\mathrm{dd}, \mathrm{J}=7.83 \mathrm{~Hz}, 2 \mathrm{H}), 6.95(\mathrm{dt}, \mathrm{J}=7.46 \mathrm{~Hz}, 2 \mathrm{H}), 4.94(\mathrm{~s}, 1 \mathrm{H}) ;{ }^{13} \mathrm{C} \mathrm{NMR}\left(50 \mathrm{MHz}, \mathrm{CDCl}_{3}\right) \delta: 158.07$, 152.96, 131.30, 130.78, 119.87, 116.71, 116.47. MS found for $[\mathrm{M}+\mathrm{H}]^{+}$138.0738. Anal. Calcd C, 61.31; H, 5.14; N, 10.21. Found: C, 60.75; H, 4.99; N, 10.11.

Preparation of the library containing complexes M-OR/dioximes: $1 \mathrm{~mL}$ tubes (from VWR) are placed in a 96 well plate in glove box protected from oxygen and moisture. Metal precursors $\left(2,25.10^{-5} \mathrm{~mol}\right)$ are disposed as follows: columns $2\left(\mathrm{Zr}\left({ }^{\mathrm{n}} \mathrm{OPr}\right) 4,10,5 \mathrm{mg}, 10,1 \mu \mathrm{L}\right)$, columns 3 $\left(\mathrm{Zr}\left({ }^{\mathrm{i} O P r}\right)_{4}, 8,7 \mathrm{mg}\right)$, columns $4\left(\mathrm{Zr}\left({ }^{\mathrm{n}} \mathrm{OBu}\right)_{4}, 10,8 \mathrm{mg}, 10,3 \mu \mathrm{L}\right)$, columns $5\left(\mathrm{Ti}\left({ }^{\mathrm{n}} \mathrm{OPr}\right)_{4}, 6,5 \mathrm{mg}, 6,3\right.$ $\mu \mathrm{L})$, columns $6\left(\mathrm{Ti}\left({ }^{\mathrm{i} O P r}\right)_{4}, 6,5 \mathrm{mg}, 6,8 \mu \mathrm{L}\right)$ and columns $7\left(\mathrm{Ti}\left({ }^{\mathrm{n}} \mathrm{OBu}\right)_{4}, 7,9 \mathrm{mg}, 7,9 \mu \mathrm{L}\right)$. Then, the dioxime ligands $\underline{\mathbf{1}}, \underline{\mathbf{2}}, \underline{\mathbf{3}}, \underline{\mathbf{5}}$ and $\underline{\mathbf{6}}\left(2,25.10^{-5}(1: 1)\right.$ to $\left.4,5.10^{-5} \mathrm{~mol}(1: 2)\right)$ are added in rows B to F respectively. Each tube in each column is charged with THF $(50 \mu \mathrm{L})$ and stirred with a magnetic stir bar during 4 hours.

Preparation of the library containing complexes M-OR/mono-oximes: $1 \mathrm{~mL}$ tubes (from VWR) are placed in a 96 well plate in glove box protected from oxygen and moisture. Metal precursors $\left(2,25.10^{-5} \mathrm{~mol}\right)$ are disposed as follows: columns $2\left(\mathrm{Zr}\left({ }^{\mathrm{n}} \mathrm{OPr}\right)_{4}, 10,5 \mathrm{mg}, 10,1 \mu \mathrm{L}\right)$, columns $3\left(\mathrm{Zr}\left({ }^{\mathrm{i} O P r}\right)_{4}, 8,7 \mathrm{mg}\right)$, columns $4\left(\mathrm{Zr}\left({ }^{\mathrm{n}} \mathrm{OBu}\right)_{4}, 10,8 \mathrm{mg}, 10,3 \mu \mathrm{L}\right)$, columns $5\left(\mathrm{Ti}\left({ }^{\mathrm{n}} \mathrm{OPr}\right)_{4}\right.$, 6,5 mg, 6,3 $\mu \mathrm{L})$, columns $6\left(\mathrm{Ti}\left({ }^{\mathrm{i}} \mathrm{OPr}\right)_{4}, 6,5 \mathrm{mg}, 6,8 \mu \mathrm{L}\right)$ and columns $7\left(\mathrm{Ti}\left({ }^{\mathrm{n}} \mathrm{OBu}\right)_{4}, 7,9 \mathrm{mg}, 7,9\right.$ $\mu \mathrm{L})$. Then, the mono-oxime ligands $\underline{\mathbf{4}}, \underline{\mathbf{7}}, \underline{\mathbf{8}}, \underline{\mathbf{9}}, \underline{\mathbf{1 0}}, \underline{\mathbf{1 1}}, \underline{\mathbf{1 2}}$ and $\underline{\mathbf{1 3}}\left(4,5.10^{-5}(1: 2)\right.$ to $\left.9.10^{-5} \mathrm{~mol}(1: 4)\right)$ 
are added in rows B to I respectively. Each tube in each column is charged with THF (50 $\mu \mathrm{L})$ and stirred with a magnetic stir bar during 4 hours.

General procedure for parallel HTS method: SMP1 (55 g) was introduced in a large plastic vessel $\left(185^{*} 95^{*} 15 \mathrm{~mm}\right)$. Another 96 well plate B was slowly disposed on the plastic tank to allow the viscous liquid to fill to 96 wells by capillarity. By this way, 96 identical samples of prepolymer are generated without any transfer by multichannel pipette or individual weighting. Each reactor has an $8 \mathrm{~mm}$ diameter and $8 \mathrm{~mm}$ height. Catalytic systems were then transferred from the plate A into the 96 wells of plate B with a multichannel pipette to form a film at the surface of each reactor. Then, the plate was removed of glove box and was disposed into laboratory in contact with ambient moisture. The cross-linking time was followed every 5 minutes during 1 hour at room temperature (classical conditions in the laboratory are $55 \% \mathrm{H}_{2} \mathrm{O}$ and $23^{\circ} \mathrm{C}$ ).

General procedure for the cross-linking of SMP1 in bulk: Catalysts $\left(4,5.10^{-4} \mathrm{~mol}\right)$ and THF $(100 \mu \mathrm{L})$ were added in $1 \mathrm{~mL}$ tubes (from VWR). Mixtures were stirred with a magnetic stir bar during 1 hour at room temperature. SMP1 prepolymer $(10 \mathrm{~g})$ was introduced in a plastic cup (diameter $50 \mathrm{~mm}$ and height $30 \mathrm{~mm}$ ). Catalytic systems were introduced in the plastic cup and stirred with SMP1 during 1 minute. Cross-linking time was evaluated by touching the surface every 5 minutes during 1 hour, then every 30 minutes until 8 hours and every day until 1 week.

General procedure for the cross-linking of sealant containing SMP1 in bulk: Catalysts $\left(4,5.10^{-}\right.$ ${ }^{4} \mathrm{~mol}$ ) and THF $(100 \mu \mathrm{L})$ were added in $1 \mathrm{~mL}$ tubes (from VWR). Mixtures were stirred with a magnetic stir bar during $1 \mathrm{~h}$ at room temperature. SMP1 prepolymer (5 g) and Calcium carbonate (Calofort SV, $5 \mathrm{~g}$ ) were introduced in a plastic cup (diameter 50mm and height $30 \mathrm{~mm}$ ) and stirred with a mechanical stirrer during 10 minutes. Catalytic systems were introduced in the plastic cup and stirred with prepolymer during 1 minute. Cross-linking time was evaluated by touching the 
surface every 5 minutes during 1 hour, then every 30 minutes until 8 hours and every day until 1 week.

General procedure to determine stability of the sealant: same procedure that for the crosslinking of sealant containing SMP1 but this mixture is introduced in a cartridge and put in an oven at $40^{\circ} \mathrm{C}$ during 1 month. After 1 month, the cartridge was removed and the cross-linking time was evaluated by classical method in room condition (classical conditions in the laboratory are $55 \% \mathrm{H}_{2} \mathrm{O}$ and $23^{\circ} \mathrm{C}$ ). 


\section{RESULTS AND DISCUSSION}

\section{Screening of alkoxide/dioxime systems for SMP1}

Zirconium- and titanium-based alkoxides are unstable in the presence of moisture. To improve their behavior during storage, some chelating agents, such as acetylacetone can be used. Buyuktas et $a l{ }^{25}$ reported on the synthesis and stability of systems that provided a reaction between zirconium or titanium alkoxides with dimethylglyoxime. In this work, only two molecules of dioxime can participate in the coordination of one molecule of $\operatorname{Ti}\left({ }^{\mathrm{n}} \mathrm{OBu}\right)_{4}$ or $\mathrm{Zr}\left({ }^{\mathrm{n}} \mathrm{OBu}\right)_{4}$ to form MO-N bonds. In our case, several oximes were evaluated instead of the classical chelating agents to test their potential for cross-linking SMPs. Thus, the curing times of alkoxide/dioxime systems at two different M/L ratios (1/1 and 1/2) were measured by the HTS method. For the results obtained with the 1/1 ratio (Fig. 6a), all the systems can be organized into four categories (i.e., fast, medium and slow curing times or inefficient after 1 hour). According to this classification, it is logical to expect that fast systems are better than the others. In fact, we looked for new ligands able to stabilize alkoxides, meaning the better hits are systems able to modify the curing time of alkoxides alone. Indeed, interesting hits will be alkoxide/oxime couples capable of stabilizing alkoxides while maintaining a relatively good curing time. Therefore, plots including the curing time (CT) were transformed into new ones with a $\triangle$ parameter (Fig. 6b) to identify more interesting hits. The $\triangle$ parameter is described by the equation:

$\Delta=\mathrm{CT}($ alkoxideloxime system $)-\mathrm{CT}($ corresponding alkoxide $)$

When $\Delta$ is equal to 0 , there is no modification of the curing time between a new system and alkoxides used alone (shown in red). At this stage, there are two hypotheses: a) there is no reaction between the ligand and the alkoxide, meaning the alkoxide reacts by itself, or b) there is a complexation that is not able to control the reaction. In contrast, when $\Delta$ is greater than 0 , this 
means that alkoxide/oxime systems (shown in blue) are able to control the curing time of the initial alkoxide used.

- The use of the dioxime alone (without metal) as catalyst does not allow the cross-linking of SMP1 after 1 hour (column 1, row B to F).

- All akoxides are quite active (column 2 to 7 , row A), but it is well known that they are unstable in the presence of moisture. The curing time of many systems is equal to the curing time of the corresponding alkoxide $\left(\mathrm{Zr}\left({ }^{\mathrm{n}} \mathrm{OPr}\right)_{4}\right.$ in column $2, \mathrm{Zr}\left({ }^{\mathrm{i}} \mathrm{OPr}\right)_{4}$ in column 3 and $\mathrm{Ti}\left({ }^{\mathrm{i} O P r}\right)_{4}$ in column 6).

- Using an M/L ratio equal to $1 / 1$, only 4 systems among the 36 have a $\Delta$ value different from 0 , meaning there are only 4 interesting hits for our application: $\mathrm{Zr}\left({ }^{\mathrm{n}} \mathrm{OBu}\right)_{4}+\underline{\mathbf{2}}$, $\operatorname{Ti}\left({ }^{\mathrm{n}} \mathrm{OPr}\right)_{4}+\underline{\mathbf{2}}, \operatorname{Ti}\left({ }^{\mathrm{n}} \mathrm{OBu}\right)_{4}+\underline{\mathbf{2}}$ and $\mathrm{Ti}\left({ }^{\mathrm{n}} \mathrm{OBu}\right)_{4}+\underline{\mathbf{5}}$. We also report the minimum differences in curing times between the system and alkoxide alone for these interesting hits, here 30 minutes.

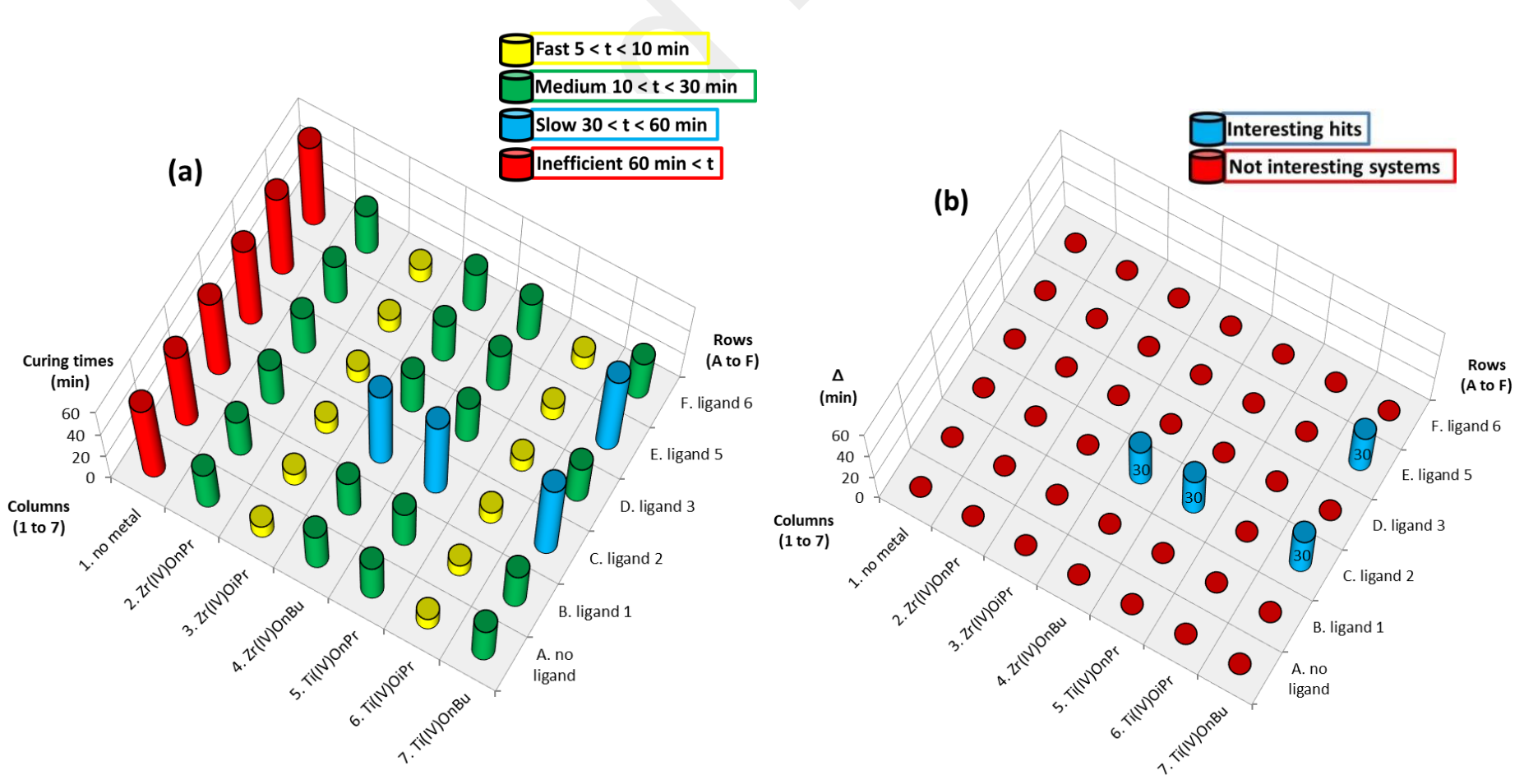

Figure 6. The curing times of alkoxide/dioxime systems with an M/L ratio of 1/1 obtained by HTS method (a) and the transformation of curing times in $\Delta$ parameter for each systems (b) 
HTS was used also to investigate alkoxide/dioxime systems with an M/L ratio equal to $1 / 2$ to observe the impact of ligands. Similarly, the curing times were also transformed into $\Delta$ values (Fig. 7).

- Using an $\mathrm{M} / \mathrm{L}$ ratio equal to $1 / 2$, the curing time of 6 systems increased (higher than 1 hour), making the determination of the $\Delta$ value impossible (cross in the graph). This means that the new zirconium- and titanium-based complexes are inactive for $\mathrm{Zr}\left({ }^{\mathrm{n}} \mathrm{OBu}\right)_{4}+\underline{\mathbf{2}}, \underline{\mathbf{5}}$ and $\underline{\mathbf{6}}, \operatorname{Ti}\left({ }^{\mathrm{n}} \mathrm{OPr}\right)_{4}+\underline{\mathbf{2}}$ and $\operatorname{Ti}\left({ }^{\mathrm{i}} \mathrm{OPr}\right)_{4}+\underline{\mathbf{2}}$ and $\underline{\mathbf{5}}$. The creation of catalytic species is due to the reaction of these systems with moisture to form a hydroxyalkoxide as well as for the tin catalyst. It is suggested that the hindrance of these 6 systems is more important when the amount of oxime increases and involves a lower reactivity with moisture, leading to an excessive curing time.

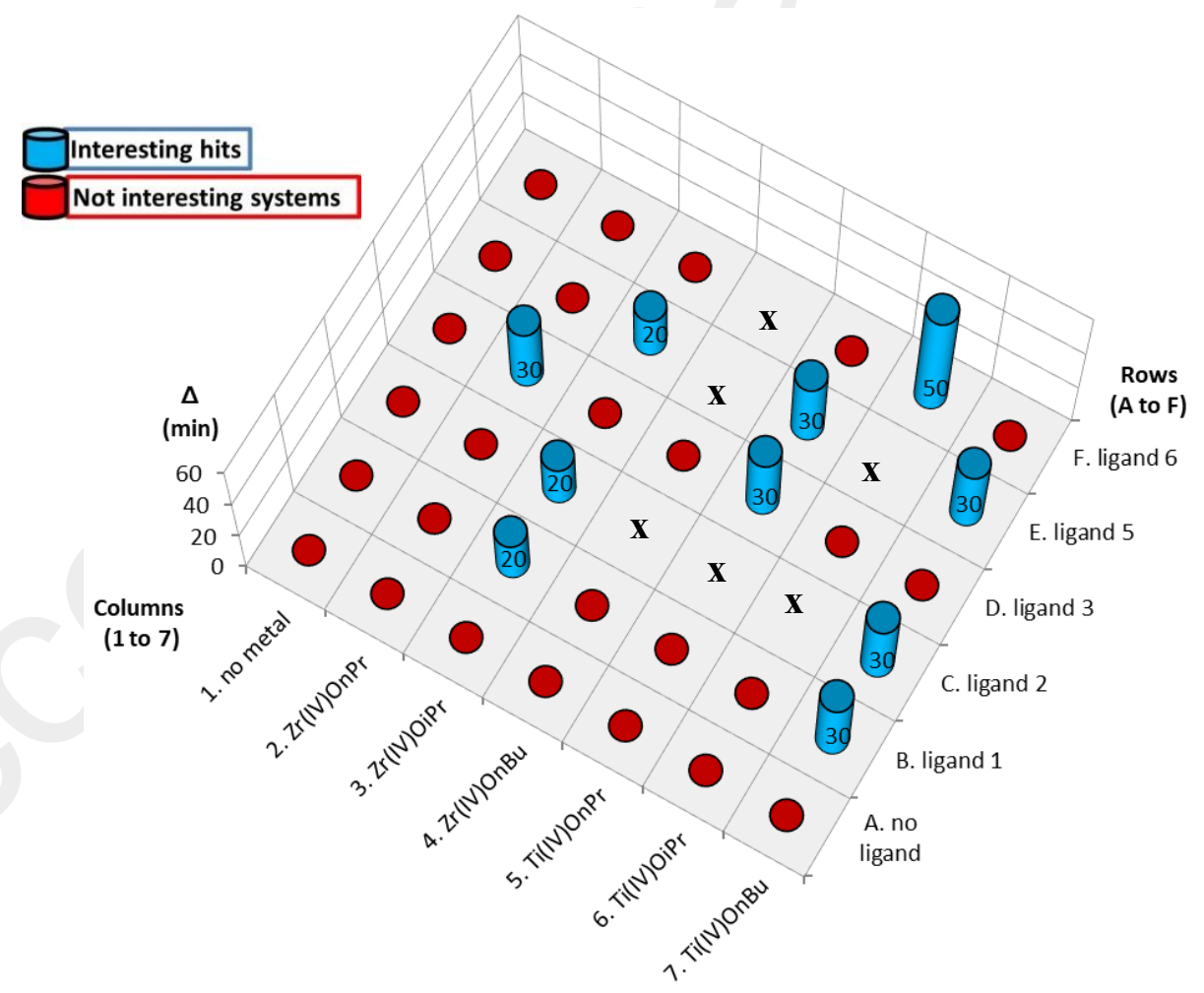

Figure 7. The curing times of alkoxide/dioxime systems with an M/L ratio of $1 / 2$ transformed into $\Delta$ parameter 
- The curing time for some systems containing $\mathrm{Zr}\left({ }^{\mathrm{i}} \mathrm{OPr}\right)_{4}$ or $\mathrm{Ti}\left({ }^{\mathrm{i}} \mathrm{OPr}\right)_{4}$ decreased using an $\mathrm{M} / \mathrm{L}$ ratio equal to $1 / 2$, whereas there was no modification of curing times at $1 / 1$.

- Considering only efficient systems with a $1 / 2$ ratio, such as $\mathrm{Zr}\left({ }^{\mathrm{i} O P r}\right)_{4}+\underline{\mathbf{1}}, \mathrm{Zr}\left({ }^{\mathrm{i} O P r}\right)_{4}+\underline{\mathbf{2}}$, $\operatorname{Zr}\left({ }^{\mathrm{i} O P r}\right)_{4}+\underline{\mathbf{5}}, \operatorname{Ti}\left({ }^{\mathrm{i} O P r}\right)_{4}+\underline{\mathbf{6}}$ and $\mathrm{Zr}\left({ }^{\mathrm{n}} \mathrm{OPr}\right)_{4}+\underline{\mathbf{3}}$, the curing time increases. The efficiency of $\mathrm{Ti}\left({ }^{\mathrm{n}} \mathrm{OBu}\right)_{4}+\underline{\mathbf{5}}$ is the same at $1 / 1$ and $1 / 2$. Therefore, this system will be further studied only at a $1 / 1$ ratio, which is enough to increase the stability and maintain a relatively good curing time.

- There are no interesting systems containing $\mathrm{Zr}\left({ }^{\mathrm{n}} \mathrm{OBu}\right)_{4}$ at a $1 / 2$ ratio, as all of these systems, which have different curing time than with alkoxides alone, are inefficient after 1 hour of reaction.

- $\operatorname{Ti}\left({ }^{\mathrm{n}} \mathrm{OPr}\right)_{4}+\underline{\mathbf{3}}$ and $\operatorname{Ti}\left({ }^{\mathrm{n}} \mathrm{OPr}\right)_{4}+\underline{\mathbf{5}}$ are interesting only at the $1 / 2$ ratio.

- The reactivity of the $\operatorname{Ti}\left({ }^{\mathrm{i} O P r}\right)_{4}+\underline{\mathbf{6}}, \mathrm{Ti}\left({ }^{\mathrm{n}} \mathrm{OBu}\right)_{4}+\underline{\mathbf{1}}$ and $\mathrm{Ti}\left({ }^{\mathrm{n}} \mathrm{OBu}\right)_{4}+\underline{\mathbf{2}}$ systems decreases compared to alkoxides alone using a $1 / 2$ ratio.

Thus, all of these systems are studied in a second step to determine their real cross-linking time. In summary, among the 72 alkoxide/dioxime systems tested by the HTS method, only 12 were detected as promising hits. Indeed, they induce the cross-linking of SMP1 by generating a steric hindrance around the alkoxide to control the hydrolysis rate. Thereby, it is logical to hope that these systems will be more stable in cartridges than alkoxides alone. Despite the good results obtained with $\mathrm{Zr}\left({ }^{\mathrm{i} O P r}\right)_{4}+\underline{\mathbf{1}}, \mathrm{Zr}\left({ }^{\mathrm{i} O P r}\right)_{4}+\underline{\mathbf{2}}, \mathrm{Zr}\left({ }^{\mathrm{i} O P r}\right)_{4}+\underline{\mathbf{5}}$ and $\mathrm{Ti}\left({ }^{\mathrm{i} O P r}\right)_{4}+\underline{\mathbf{6}}$, it is not possible to go further to determine their real cross-linking times, as $\mathrm{Zr}\left({ }^{\mathrm{i}} \mathrm{OPr}\right)_{4}$ and $\mathrm{Ti}\left({ }^{\mathrm{i}} \mathrm{OPr}\right)_{4}$ are not available from industrial suppliers with stable compositions between the different samples. Therefore, only 8 alkoxide/dioxime systems will be studied. 


\section{Screening of alkoxide/mono-oxime systems for SMP1}

The reaction between mono-oximes and alkoxides consists of the nucleophilic substitution of alcohol groups to form metallic oximate complexes ${ }^{26}$. Theoretically, one to four molecules of mono-oximes can react with one molecule of titanium- or zirconium-based alkoxides. Therefore, the HTS method was used and the corresponding curing times were transformed into $\Delta$ values for two $\mathrm{M} / \mathrm{L}$ ratios (1/2 and 1/4). For a 1/2 ratio (Fig. 8) for the alkoxide/dioxime systems, we look to detect the mono-oximes able to modify the curing time of alkoxides alone. Surprisingly, in several cases, the $\Delta$ parameter is lower than 0 , meaning that the alkoxide/mono-oxime systems (shown in yellow) decrease the curing time of the initial alkoxide used and accelerate their reactivity. In fact, by using mono-oximes, several systems are found to have faster curing times than alkoxides and may be a potential option to replace organotin compounds. For example, five systems, namely, $\mathrm{Zr}\left({ }^{\mathrm{n}} \mathrm{OPr}\right)_{4}+\underline{\mathbf{4}}, \mathrm{Zr}\left({ }^{\mathrm{n}} \mathrm{OPr}\right)_{4}+\underline{\mathbf{7}}, \mathrm{Zr}\left({ }^{\mathrm{n}} \mathrm{OPr}\right)_{4}+\underline{\mathbf{8}}, \mathrm{Zr}\left({ }^{\mathrm{n}} \mathrm{OPr}\right)_{4}+\underline{\mathbf{9}}$ and $\mathrm{Zr}\left({ }^{\mathrm{n}} \mathrm{OPr}\right)_{4}+\underline{\mathbf{1 1}}$ are more efficient than $\mathrm{Zr}\left({ }^{\mathrm{n}} \mathrm{OPr}\right)_{4}$ alone.

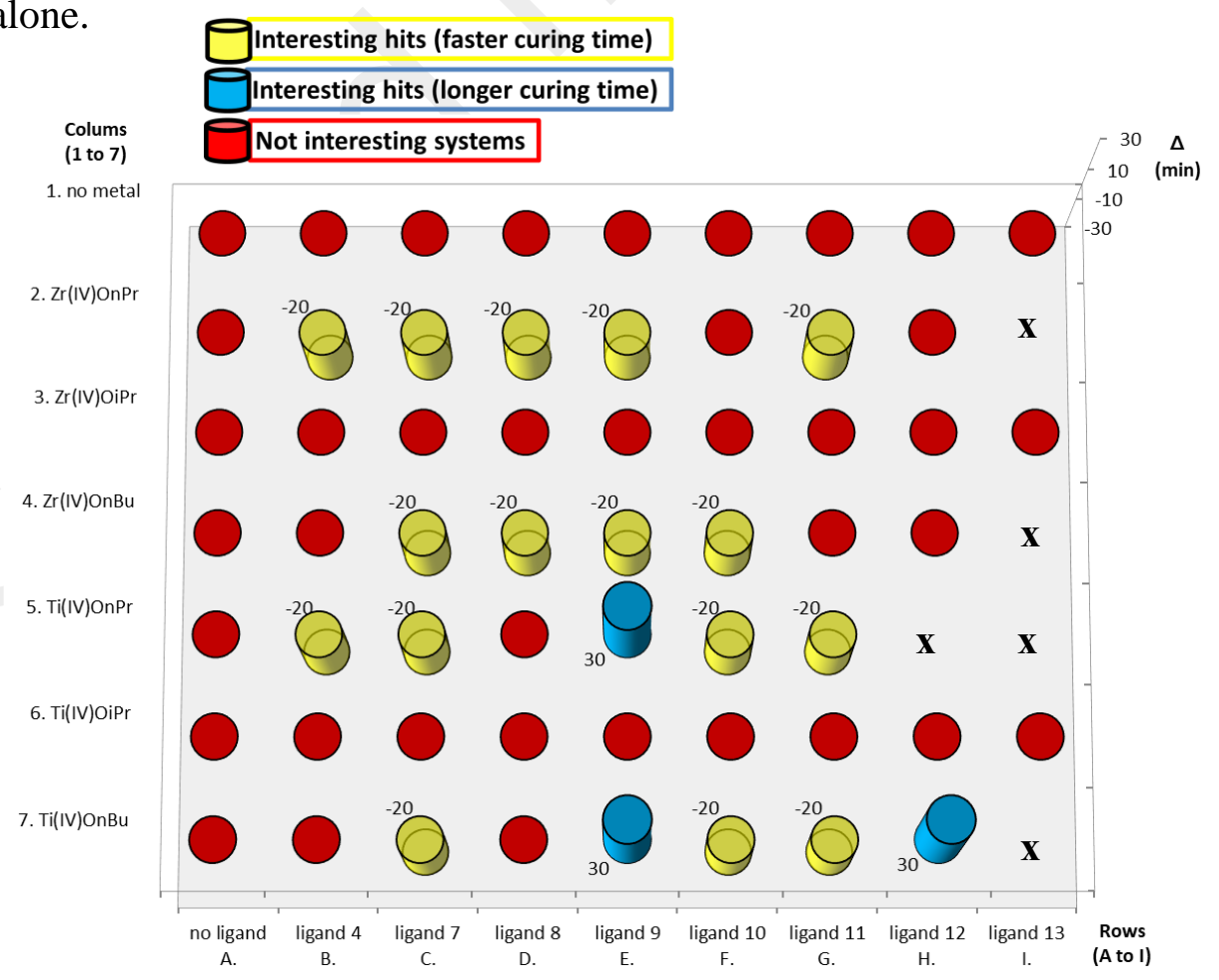

Figure 8. The curing times of alkoxide/mono-oxime systems with an $\mathrm{M} / \mathrm{L}$ ratio of $1 / 2$ transformed into $\Delta$ parameter 
Furthermore, the systems provided by the combination of salicylaldoxime $\underline{\mathbf{1 3}}$ and $\mathrm{Zr}\left({ }^{\mathrm{n}} \mathrm{OPr}\right)_{4}$, $\mathrm{Zr}\left({ }^{\mathrm{n}} \mathrm{OBu}\right)_{4}, \mathrm{Ti}\left({ }^{\mathrm{n}} \mathrm{OPr}\right)_{4}$ and $\mathrm{Ti}\left({ }^{\mathrm{n}} \mathrm{OBu}\right)_{4}$ are inefficient after 1 hour of reaction. This behavior may be explained by Buyukthas et al., indeed, the structures of the complexes formed by the reaction between the salicylaldoxime $\underline{\mathbf{1 3}}$ and acetone oxime $\underline{\mathbf{9}}$ with $\mathrm{Ti}\left({ }^{\mathrm{n}} \mathrm{OBu}\right)_{4}$ are completely different. In the first case, $\underline{\mathbf{1 3}}$ can be coordinated on titanium by the oxygen of the phenol group, but also by the nitrogen of the oxime group (Fig. 9a). In the second case, ligand $\underline{\mathbf{9}}$ involves the nucleophilic substitution of alcohol groups to form Ti-O-N bonds (Fig. 9b). Infrared analyses were performed on these complexes, indicating that there is a shift of $\mathrm{N}-\mathrm{O}$ stretching to a higher frequency from $\underline{9}$ to $\operatorname{Ti}\left({ }^{\mathrm{n}} \mathrm{OBu}\right)_{2}(\underline{\mathbf{9}})_{2}$, which can be explained by the direct interaction between titanium and oxygen atoms, shifting the electron density from nitrogen to oxygen. In our case, this effect has a great impact on the catalysis of SMP, as the titanium becomes more sensitive to moisture and thus creates more easily the active species. Therefore, systems with $\underline{\mathbf{1 3}}$ which does not contain the MO-N bonds, are less efficient than alkoxides alone, whereas systems with other mono-oximes are more efficient than alkoxides alone or at least have the same efficiency. However, it is worth nothing that a longer curing time (shown in green) can be obtained, such as for $\operatorname{Ti}\left({ }^{\mathrm{n}} \mathrm{OPr}\right)_{4}+\underline{\mathbf{9}}$, $\operatorname{Ti}\left({ }^{\mathrm{n}} \mathrm{OBu}\right)_{4}+\underline{\mathbf{9}}$ and $\mathrm{Ti}\left({ }^{\mathrm{n}} \mathrm{OBu}\right)_{4}+\underline{\mathbf{1 2}}$. These three exceptions are probably due to the structure of the complexes formed, which can be dimer, trimer or others ${ }^{27}$. Indeed, the formation of complexes is difficult to predict, as it depends on the alkoxide/oxime couple used, but also on the solvent, temperature and moisture rate. It appears that the formation of $\mathrm{M}-\mathrm{O}-\mathrm{N}$ bonds is essential to a fast curing time. Finally, this screening allows for the detection of 16 systems for an M/L ratio of 1/2, that have better curing times than when alkoxides are used alone. 
(b)

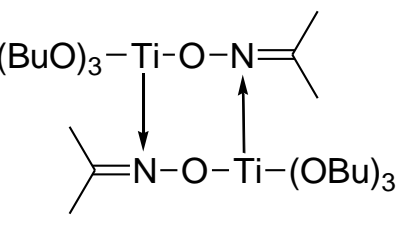

Figure 9. Possible structures of (a) $\operatorname{Ti}\left({ }^{\mathrm{n}} \mathrm{OBu}\right)_{2}(\underline{13})_{2}$ and (b) $\mathrm{Ti}\left({ }^{\mathrm{n}} \mathrm{OBu}\right)_{3}(\underline{9})$

The HTS method was also used to screen alkoxide/mono-oximes systems with an M/L ratio equal to $1 / 4$ (Fig. 10) to compare the substitution effect for the cross-linking of SMP1. However, there were no differences between the $1 / 2$ and $1 / 4$ ratios excepted for $\operatorname{Ti}\left({ }^{n} \mathrm{OBu}\right)_{4}+\underline{\mathbf{1 2}}$, which becomes inefficient after 1 hour at a $\mathrm{M} / \mathrm{L}$ ratio of $1 / 4$. In fact, this may be due to some differences between interesting hits (shown in yellow), but our HTS method does not allow detection of the differences between several systems with curing times between 5 and 10 minutes.

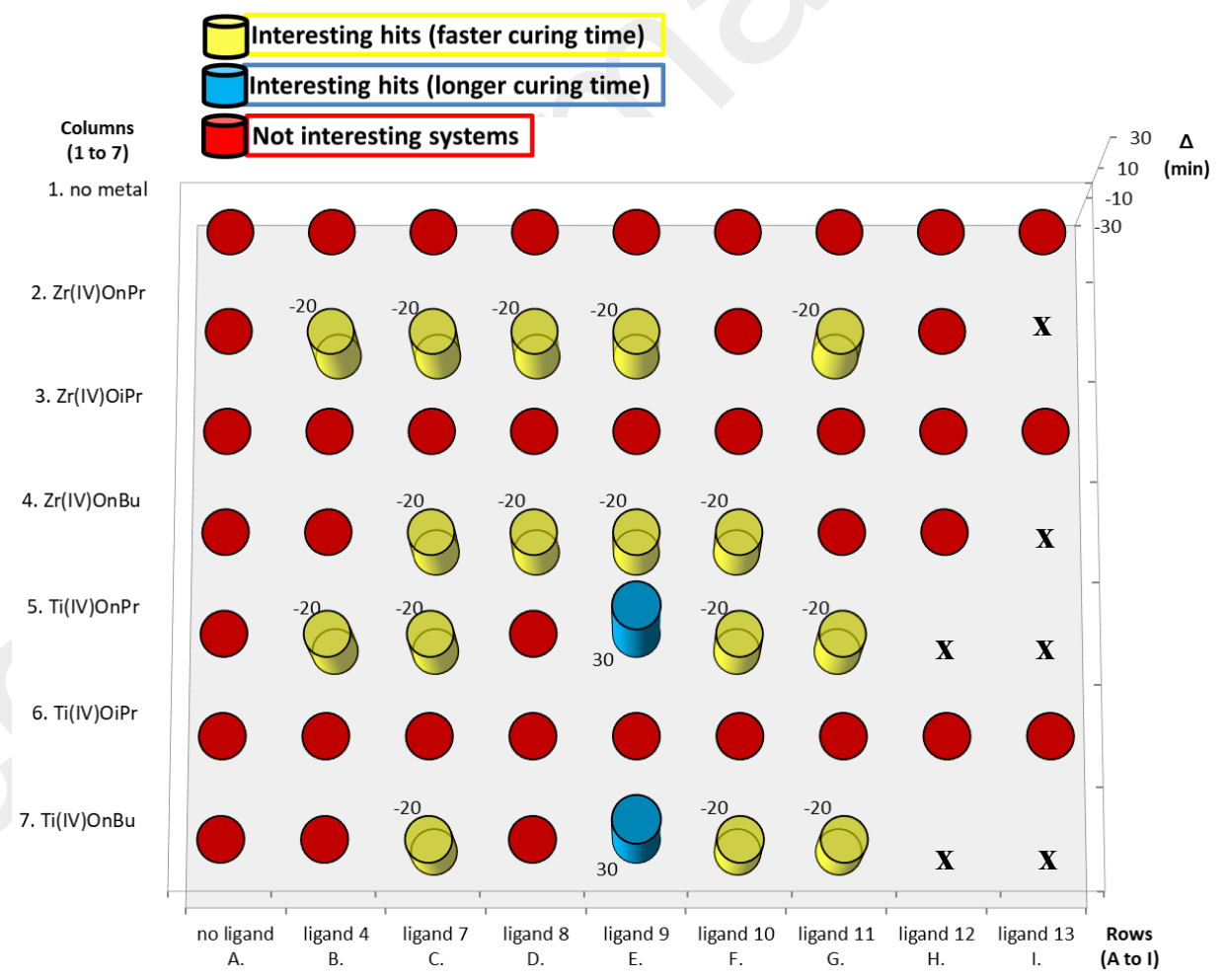

Figure 10. The curing times of alkoxide/mono-oxime systems with an $\mathrm{M} / \mathrm{L}$ ratio of $1 / 4$ transformed into $\Delta$ parameter 
In summary, among the 96 alkoxide/mono-oxime systems tested using the HTS method, 32 were detected as faster than alkoxides alone. More specifically, 16 systems are very interesting at an $\mathrm{M} / \mathrm{L}$ ratio of $1 / 2$ but also at a ratio of $1 / 4$. All these hits will be further studied to measure their real cross-linking time and check if the same order of curing time is obtained under standard conditions.

\section{Cross-linking time of interesting hits for SMP1}

The HTS method allowed the detection of several interesting hits based on alkoxide/oxime systems (i.e., 8 systems based on dioximes and 32 based on mono-oximes). The second step is to measure the real cross-linking times compared to DBTDL and zirconium- or titanium-based alkoxides. Using the same conditions (temperature, humidity and molar ratio of the catalytic system), the reactions were performed in bulk conditions for $10 \mathrm{~g}$ of SMP1 prepolymer and fast mixing of the mixture. Then, the cross-linking times were determined by touching the surface with a needle several times (standard method) by using alkoxide/dioxime systems (Table 1) and alkoxide/monooxime systems (Table 2).

Table 1 Cross-linking times of efficient systems based on alkoxide/dioxime by standard method at room temperature on SMP1.

\begin{tabular}{lcc}
\hline Catalysts & M/L ratio & $\begin{array}{c}\text { Cross-linking time } \\
\text { (min) }\end{array}$ \\
\hline $\mathrm{DBTDL}$ & - & 150 \\
$\mathrm{Zr}\left({ }^{\mathrm{n}} \mathrm{OPr}\right)_{4}$ & - & 30 \\
$\mathrm{Zr}\left({ }^{\mathrm{n}} \mathrm{OBu}\right)_{4}$ & - & 90 \\
$\mathrm{Ti}\left({ }^{\mathrm{n}} \mathrm{OPr}\right)_{4}$ & - & 30 \\
$\mathrm{Ti}\left({ }^{\mathrm{n}} \mathrm{OBu}\right)_{4}$ & - & 60 \\
\hline $\mathrm{Zr}\left({ }^{\mathrm{n}} \mathrm{OPr}\right)_{4}+\underline{3}$ & $1 / 2$ & 180 \\
$\mathrm{Zr}\left({ }^{\mathrm{n}} \mathrm{OBu}\right)_{4}+\underline{2}$ & $1 / 1$ & 480 \\
$\mathrm{Ti}\left({ }^{\mathrm{n}} \mathrm{OPr}\right)_{4}+\underline{\underline{2}}$ & $1 / 1$ & 360 \\
$\mathrm{Ti}\left({ }^{\mathrm{n}} \mathrm{OPr}\right)_{4}+\underline{3}$ & $1 / 2$ & 480 \\
$\mathrm{Ti}\left({ }^{\mathrm{n}} \mathrm{OPr}\right)_{4}+\underline{5}$ & $1 / 2$ & 1440 \\
$\mathrm{Ti}\left({ }^{\mathrm{n}} \mathrm{OBu}\right)_{4}+\underline{5}$ & $1 / 1$ & 480 \\
$\mathrm{Ti}\left({ }^{\mathrm{n}} \mathrm{OBu}\right)_{4}+\underline{1}$ & $1 / 2$ & 300 \\
$\mathrm{Ti}\left({ }^{\mathrm{n}} \mathrm{OBu}\right)_{4}+\underline{\underline{2}}$ & $1 / 1$ & 120 \\
\hline
\end{tabular}

The cross-linking times of zirconium- and titanium-based alkoxides are faster than the tin catalyst (DBTDL, from 30 to 90 minutes compared to 150 minutes with DBTDL). The use of dioxime 
ligands increases the cross-linking times for zirconium- and titanium-based systems, allowing a longer open time, which is important for a specific target where the adhesive has to be repositionable. The combinations of $\mathrm{Zr}\left({ }^{\mathrm{n}} \mathrm{OPr}\right)_{4}+\underline{\mathbf{3}}$ and $\mathrm{Ti}\left({ }^{\mathrm{n}} \mathrm{OBu}\right)_{4}+\underline{\mathbf{2}}$ are very close to DBTDL and may be interesting due to their potential high stability against moisture in cartridges compared to alkoxides alone.

Table 2 Cross-linking times of efficient systems based on alkoxide/mono-oxime by standard method at room temperature on SMP1.

\begin{tabular}{|c|c|c|}
\hline Catalysts & M/L ratio & $\begin{array}{c}\text { Cross-linking time } \\
(\text { min })\end{array}$ \\
\hline $\mathrm{Zr}\left({ }^{\mathrm{n}} \mathrm{OPr}\right)_{4}+\underline{4}$ & $1 / 2$ & 20 \\
\hline $\mathrm{Zr}\left({ }^{\mathrm{n}} \mathrm{OPr}\right)_{4}+\overline{\overline{7}}$ & $1 / 2$ & 10 \\
\hline $\mathrm{Zr}\left({ }^{\mathrm{n}} \mathrm{OPr}\right)_{4}+\underline{\overline{8}}$ & $1 / 2$ & 15 \\
\hline $\mathrm{Zr}\left({ }^{\mathrm{n}} \mathrm{OPr}\right)_{4}+\underline{\overline{9}}$ & $1 / 2$ & 45 \\
\hline $\mathrm{Zr}\left({ }^{\mathrm{n}} \mathrm{OPr}\right)_{4}+\overline{1} 1$ & $1 / 2$ & 10 \\
\hline $\mathrm{Zr}\left({ }^{\mathrm{n}} \mathrm{OPr}\right)_{4}+\overline{4}$ & $1 / 4$ & 25 \\
\hline $\mathrm{Zr}\left({ }^{\mathrm{n}} \mathrm{OPr}\right)_{4}+\overline{\overline{7}}$ & $1 / 4$ & 10 \\
\hline $\mathrm{Zr}\left({ }^{\mathrm{n}} \mathrm{OPr}\right)_{4}+\underline{\overline{8}}$ & $1 / 4$ & 10 \\
\hline $\mathrm{Zr}\left({ }^{\mathrm{n}} \mathrm{OPr}\right)_{4}+\underline{\overline{9}}$ & $1 / 4$ & 15 \\
\hline $\mathrm{Zr}\left({ }^{\mathrm{n}} \mathrm{OPr}\right)_{4}+\underline{\overline{1} 1}$ & $1 / 4$ & 15 \\
\hline $\mathrm{Zr}\left({ }^{\mathrm{n}} \mathrm{OBu}\right)_{4}+\underline{7}$ & $1 / 2$ & 10 \\
\hline $\mathrm{Zr}\left({ }^{\mathrm{n}} \mathrm{OBu}\right)_{4}+\underline{\overline{8}}$ & $1 / 2$ & 10 \\
\hline $\mathrm{Zr}\left({ }^{\mathrm{n}} \mathrm{OBu}\right)_{4}+\underline{\overline{9}}$ & $1 / 2$ & 20 \\
\hline $\mathrm{Zr}\left({ }^{\mathrm{n}} \mathrm{OBu}\right)_{4}+\underline{10}$ & $1 / 2$ & 20 \\
\hline $\mathrm{Zr}\left({ }^{\mathrm{n}} \mathrm{OBu}\right)_{4}+\overline{\underline{7}}$ & $1 / 4$ & 10 \\
\hline $\mathrm{Zr}\left({ }^{\mathrm{n}} \mathrm{OBu}\right)_{4}+\underline{\overline{8}}$ & $1 / 4$ & 15 \\
\hline $\mathrm{Zr}\left({ }^{\mathrm{n}} \mathrm{OBu}\right)_{4}+\underline{\overline{9}}$ & $1 / 4$ & 20 \\
\hline $\mathrm{Zr}\left({ }^{\mathrm{n}} \mathrm{OBu}\right)_{4}+\underline{\underline{10}}$ & $1 / 4$ & 20 \\
\hline $\mathrm{Ti}\left({ }^{\mathrm{n}} \mathrm{OPr}\right)_{4}+\underline{4}$ & $1 / 2$ & 10 \\
\hline $\mathrm{Ti}\left({ }^{\mathrm{n}} \mathrm{OPr}\right)_{4}+\overline{7}$ & $1 / 2$ & 15 \\
\hline $\operatorname{Ti}\left({ }^{\mathrm{n}} \mathrm{OPr}\right)_{4}+\overline{10}$ & $1 / 2$ & 40 \\
\hline $\mathrm{Ti}\left({ }^{\mathrm{n}} \mathrm{OPr}\right)_{4}+\underline{11}$ & $1 / 2$ & 30 \\
\hline $\mathrm{Ti}\left({ }^{\mathrm{n}} \mathrm{OPr}\right)_{4}+\underline{4}$ & $1 / 4$ & 15 \\
\hline $\operatorname{Ti}\left({ }^{\mathrm{n}} \mathrm{OPr}\right)_{4}+\overline{7}$ & $1 / 4$ & 10 \\
\hline $\operatorname{Ti}\left({ }^{\mathrm{n}} \mathrm{OPr}\right)_{4}+\underline{10}$ & $1 / 4$ & 20 \\
\hline $\operatorname{Ti}\left({ }^{\mathrm{n}} \mathrm{OPr}\right)_{4}+\underline{\underline{11}}$ & $1 / 4$ & 30 \\
\hline $\mathrm{Ti}\left({ }^{\mathrm{n}} \mathrm{OBu}\right)_{4}+\underline{7}$ & $1 / 2$ & 20 \\
\hline $\mathrm{Ti}\left({ }^{\mathrm{n}} \mathrm{OBu}\right)_{4}+\overline{10}$ & $1 / 2$ & 15 \\
\hline $\mathrm{Ti}\left({ }^{\mathrm{n}} \mathrm{OBu}\right)_{4}+\underline{11}$ & $1 / 2$ & 15 \\
\hline $\mathrm{Ti}\left({ }^{\mathrm{n}} \mathrm{OBu}\right)_{4}+\overline{7}$ & $1 / 4$ & 15 \\
\hline $\mathrm{Ti}\left({ }^{\mathrm{n}} \mathrm{OBu}\right)_{4}+\overline{10}$ & $1 / 4$ & 15 \\
\hline $\mathrm{Ti}\left({ }^{\mathrm{n}} \mathrm{OBu}\right)_{4}+\overline{11}$ & $1 / 4$ & 15 \\
\hline
\end{tabular}

Contrary to dioxime, the use of mono-oxime allows a shorter cross-linking time in all cases. According to the systems used, the cross-linking times vary from 10 to 45 minutes compared to 
150 minutes with DBTDL. Moreover, in most cases, the alkoxide/mono-oxime systems are better than zirconium or titanium alkoxides alone. The M/L ratio (1/2 or $1 / 4)$ slightly altered the crosslinking, meaning that the complexes formed are similar or that the cross-linking times are too fast to observe any differences. In fact, there are only two systems with shorter cross-linking times when the ratio moves from $1 / 2$ to $1 / 4$. Indeed, the cross-linking time moves from 45 to 15 minutes for $\mathrm{Zr}\left({ }^{\mathrm{n}} \mathrm{OPr}\right)_{4}+\underline{\mathbf{9}}$ and from 40 to 20 minutes for $\operatorname{Ti}\left({ }^{\mathrm{n}} \mathrm{OPr}\right)_{4}+\underline{\mathbf{1 0}}$. In these two cases, the structure of the complex formed has to be different and likely contains more $\mathrm{M}-\mathrm{O}-\mathrm{N}$ bonds, increasing the electrophilic characteristic of the metal atoms, which should be more reactive against a nucleophilic attack by moisture. Finally, many alkoxide/mono-oxime systems may be interesting when a fast cross-linking time is required, particularly for grab adhesives.

\section{Cross-linking time of some efficient catalysts for SMP1-based sealants}

The best catalysts were used to evaluate the effect of storage on the cross-linking time for SMP1based sealants. We studied the following two alkoxide/dioxime systems: $\mathrm{Zr}\left({ }^{\mathrm{n}} \mathrm{OPr}\right)_{4}+\underline{\mathbf{3}}$ and $\operatorname{Ti}\left({ }^{\mathrm{n}} \mathrm{OBu}\right)_{4}+\underline{\mathbf{2}}$, and only 10 alkoxide/mono-oxime systems were used to determine an initial idea of the stability. Thus, the cross-linking times for fresh product and after storage were determined (Table 3). The employment of zirconium and titanium alkoxides alone induces a longer crosslinking time after storage due to their high moisture-sensitive behavior involving condensation into themselves. The cross-linking times of the two alkoxide/dioxime systems slightly increased after the storage: 75 to 90 and 45 to 55 minutes, respectively. This is also the case for the $\mathrm{Zr}\left({ }^{\mathrm{n}} \mathrm{OPr}\right)_{4}$ $+\underline{4}$ system, which is composed of a mono-oxime as the ligand. These three catalysts possess $\mathrm{N}$ tripodal oxime as the ligand $(\underline{\mathbf{2}}, \underline{\mathbf{3}}$ and $\underline{\mathbf{4}})$. It is suggested that this hindered the process and that a stable structure formed during storage, likely due to the interaction of the central nitrogen atom with other metals or by a reaction between a free oxime group and another metal. Then, the 
$\operatorname{Ti}\left({ }^{\mathrm{n}} \mathrm{OPr}\right)_{4}+\underline{\mathbf{7}}$ system induces instantaneous cross-linking that is difficult to control during mixing. However, this system is not very useful for adhesive applications, as a minimum setting time is necessary to generate a homogeneous mixture for bulk reactions or to apply the adhesive material onto a surface. Lastly, the cross-linking times of the six systems provided by the reaction between $\mathrm{Zr}\left({ }^{\mathrm{n}} \mathrm{OPr}\right)_{4}, \mathrm{Zr}\left({ }^{(\mathrm{O} O B u}\right)_{4}$ and $\mathrm{Ti}\left({ }^{\mathrm{n}} \mathrm{OBu}\right)_{4}$ with ligand $\underline{\mathbf{7}}$ or $\underline{\mathbf{8}}$ are faster than DBTDL and were not modified during storage. Therefore, these systems have a high potential for use as the substitute to the tin catalyst in this sealant.

Table 3 Cross-linking times of fresh product and after storage of sealant during 1 month in an oven at $40^{\circ} \mathrm{C}$ using standard method. $*=$ longer cross-linking time after storage, $* *=$ cross-linked sealant directly after storage

\begin{tabular}{|c|c|c|c|}
\hline Catalysts & $\mathrm{M} / \mathrm{L}$ ratio & $\begin{array}{l}\text { Cross-linking time } \\
\text { fresh (min) }\end{array}$ & $\begin{array}{l}\text { Cross-linking time } \\
\text { stored (min) }\end{array}$ \\
\hline DBTDL & - & 120 & 110 \\
\hline $\mathrm{Zr}\left({ }^{\mathrm{n}} \mathrm{OPr}\right)_{4}$ & - & 25 & $*$ \\
\hline $\mathrm{Zr}\left({ }^{\mathrm{n}} \mathrm{OBu}\right)_{4}$ & - & 50 & $*$ \\
\hline $\mathrm{Ti}\left({ }^{\mathrm{n}} \mathrm{OPr}\right)_{4}$ & - & 20 & $*$ \\
\hline $\mathrm{Ti}\left({ }^{\mathrm{n}} \mathrm{OBu}\right)_{4}$ & - & 30 & $*$ \\
\hline $\mathrm{Zr}\left({ }^{\mathrm{n}} \mathrm{OPr}\right)_{4}+\underline{3}$ & $1 / 2$ & 75 & 90 \\
\hline $\mathrm{Ti}\left({ }^{\mathrm{n}} \mathrm{OBu}\right)_{4}+2$ & $1 / 1$ & 45 & 55 \\
\hline $\mathrm{Zr}\left({ }^{\mathrm{n}} \mathrm{OPr}\right)_{4}+\underline{4}$ & $1 / 2$ & 15 & 20 \\
\hline $\left.\mathrm{Zr}\left({ }^{\mathrm{n}} \mathrm{OPr}\right)\right)_{4}+\frac{1}{4}$ & $1 / 4$ & 20 & 30 \\
\hline $\mathrm{Zr}\left({ }^{\mathrm{n}} \mathrm{OPr}\right)_{4}+\overline{\overline{7}}$ & $1 / 2$ & $<5$ & $<5$ \\
\hline $\mathrm{Zr}\left({ }^{\mathrm{n}} \mathrm{OBu}\right)_{4}+\underline{7}$ & $1 / 2$ & $<5$ & $<5$ \\
\hline $\mathrm{Zr}\left({ }^{\mathrm{n}} \mathrm{OPr}\right)_{4}+\underline{8}$ & $1 / 2$ & $<5$ & $<5$ \\
\hline $\mathrm{Zr}\left({ }^{\mathrm{n}} \mathrm{OBu}\right)_{4}+\overline{8}$ & $1 / 2$ & $<5$ & $<5$ \\
\hline $\mathrm{Ti}\left({ }^{\mathrm{n}} \mathrm{OBu}\right)_{4}+\frac{7}{7}$ & $1 / 2$ & $<5$ & $<5$ \\
\hline $\mathrm{Ti}\left({ }^{\mathrm{n}} \mathrm{OBu}\right)_{4}+\overline{7}$ & $1 / 4$ & $<5$ & $<5$ \\
\hline $\mathrm{Ti}\left({ }^{\mathrm{n}} \mathrm{OPr}\right)_{4}+\underline{\overline{7}}$ & $1 / 2$ & Instantaneous & $* *$ \\
\hline $\mathrm{Ti}\left({ }^{\mathrm{n}} \mathrm{OPr}\right)_{4}+\overline{7}$ & $1 / 4$ & Instantaneous & $* *$ \\
\hline
\end{tabular}

\section{CONCLUSIONS}

The use of oxime as a chelating agent instead of acetylacetone allowed us to identify a new library of catalysts to cross-link silyloxane polymer. An HTS method was used to perform a fast comparison of 156 alkoxide/oxime-based systems for the cross-linking of SMP. This rapid method allowed the detection of approximately 40 efficient systems and extraction of the better hits, which 
were analyzed in a second step to determine their cross-linking times with the SMP1 polymer. The study of alkoxide/dioxime systems allowed the detection of two new systems: $\mathrm{Zr}\left({ }^{\mathrm{n}} \mathrm{OPr}\right)_{4}+\underline{\mathbf{3}}$ and $\mathrm{Ti}\left({ }^{\mathrm{n}} \mathrm{OBu}\right)_{4}+\underline{\mathbf{2}}$, which are closer to the performance of DBTDL. For alkoxide/mono-oxime systems, many are better than DBTDL, mainly the six systems operating via the reaction between $\mathrm{Zr}\left({ }^{\mathrm{n}} \mathrm{OPr}\right)_{4}, \mathrm{Zr}\left({ }^{\mathrm{n}} \mathrm{OBu}\right)_{4}$ and $\mathrm{Ti}\left({ }^{\mathrm{n}} \mathrm{OBu}\right)_{4}$ with ligand $\underline{\mathbf{7}}$ or $\underline{\mathbf{8}}$. These catalysts could be used in two types of applications: repositionable adhesives to bond two surfaces (dioxime-based systems) and fastsetting adhesives (mono-oxime based systems). Finally, the high efficiency and stability of alkoxide/oxime systems were established here and show the great potential of this library as an alternative to tin catalysts for the cross-linking of an adhesive and a sealant.

\section{ACKNOWLEDGEMENT}

The authors gratefully acknowledge CNRS, ANRT, BOSTIK and TOTAL for their financial support.

\section{ASSOCIATED CONTENTS}

Supporting information. preparation procedures, chemical schemes, NMR spectra of oximebased compounds. 


\section{REFERENCES}

1 (a) Maudgal, S.; St Clair, TL. Preparation and properties of silane-endcapped polyimide adhesives. Int. J. Adhes. Adhes. 1984, 4, 129-132. (b) US 8,012,302 B2. Moisture-curing compositions containing silane-functional polymers and aminosilane adducts with good adhesive properties. Sika Technology AG 2011.

2 (a) Lauriks, L.; Wouters, I.; Belis, J. Compressive and lap shear tests on traditional putty and polymer sealants. Int. J. Adhes. Adhes. 2016, 64, 109-115. (b) Foster, V.R. Polymers in caulking and sealant materials. J. Chem. Educ. 1987, 64, 861-865. (c) US 8,501,903 B2. Urea-bonded alkoxysilanes for use in sealants and adhesives. Henkel AG 2013.

3 (a) Meera, K.M.S.; Sankar, R.M.; Jaisankar, S.N. Physicochemical studies on polyurethane/siloxane cross-linked films for hydrophobic surfaces by the sol-gel process. J. Phys. Chem. B 2013, 117, 2682-2694. (b) Alyamac, E.; Gu, H.; Soucek, M.D., Qiu, S.; Buchheit, R.G. Alkoxysilane oligomer modified epoxide primers. Prog. Org. Coat. 2012, 74, 67-81.

${ }^{4}$ Kregiel, D. Advances in biofilm control for food and beverage industry using organo-silane technology: A review. Food Control 2014, 40, 32-40.

${ }^{5}$ Saikia, D.; Wu, C.G.; Fang, J.; Tsai, L.D; Kao, H.M. Organic-inorganic hybrid polymer electrolytes based on polyether diamine, alkoxysilane, and trichlorotriazine: Synthesis, characterization, and electrochemical applications. J. of Power Sources 2014, 269, 651-660.

${ }^{6}$ Kaddami, H.; Surivet, F.; Gérard, J.F.; Lam, T.M.; Pascault, J.P. Hybrid organic-inorganic materials synthesized by reaction with alkoxysilanes: Effect of the acid-to-alkoxide ratio on morphology. J. Inorg. Organomet. Polym. 1994, 4, 183-198. 
7 Ni, H.; Skaja, A.D.; Soucek, M.D. Acid-catalyzed moisture-curing polyurea/polysiloxane ceramer coatings. Prog. In Organic Coatings 2000, 40, 175-184.

${ }^{8}$ Brinker, C.J.; Keefer, K.D.; Schaefer, D.W.; Ashley, C.S. Sol-gel transition in simple silicates. J. of Non-Cryst. Solids 1982, 48, 47-64.

9 US 8,124,690 B2. Moisture curable polymer having SiF group, and curable composition containing the same. Kaneka Corporation 2012.

${ }^{10}$ EP 2813528 A1. Curable composition on the basis of polyethers containing alkoxysilane groups and a phosphazene base. Sika Technology AG 2014.

${ }^{11}$ Burkhalter, R.S.; Hogue, C.L.; Smith, D.L.; Sonner, S.M.; Winningham, M.J.; Yougman, R.E. Controlled tin catalyzed hydrolysis of 3-acryloxypropyltrimethoxysilane with mono- and multifunctional mercaptans. J. Organomet. Chem. 2013, 724, 213-224.

${ }^{12}$ US 4,956,435 Neutral cure silicone sealants. Dow Corning Corporation 1990.

13 (a) Huber, M.P.; Kelch, S.; Berke, H. FTIR investigations on hydrolysis and condensation reactions of alkoxysilane terminated polymers for use in adhesives and sealants. Int. J. Adhes. Adhes. 2016, 64, 153-162. (b) US 9,321,878 B2. Process for the preparation of silylated polyurethane polymers using titanium-containing and zirconium-containing catalysts. Momentive Performance Materials 2016.

14 (a) Guglielmi, M.; Carturan, G.; Precursors for sol-gel preparations. J. of Non-Cryst. Solids 1988, 100, 16-30. (b) Sanchez, C.; Livage, J.; Henry, M.; Babonneau, F. Chemical modification of alkoxide precursors. J. of Non-Cryst. Solids 1988, 100, 65-76. (c) US 9,376,525 B2. Curable composition and cured synthetic resin using same. MIE University 2015.

15 Mendez-Vivar, J.; Brinker, C.J. Development of Two New Approaches for Preparation of Zirconium Silicate Systems at Low Temperature. J. Sol-Gel Technol. 1994, 2, 393-397. 
${ }^{16}$ Verma, A.; Kar, M.; Singh, D.P. Aging effect of diethanolamine derived precursor sol on TiO2 films deposited at different annealing temperature. J. Sol-Gel Technol. 2010, 54, 129-138.

${ }^{17}$ Mehrotra, R.C.; Rai, A.K.; Singh, A.; Bohra, R. Oxime and hydroxylamine derivatives of metals and metalloids. Inorganica Chimica Acta 1975, 13, 91-103.

18 WO2007/009977 A1. Polymerization catalyst system based on dioxime ligands. Total Petrochemicals/CNRS 2007.

19 (a) Nicholson, G.A.; Lazarus, C.R.; McCormick, B.J. Copper(II) complexes derived from 2,6Diacetylpyridine dioxime. Inorg. Chem. 1980, 19, 192-195. (b) El-Dissouky, A.; Mohamed, G.B.; El-Sonbati, A.Z. Metal Chelates of heterocyclic nitrogen-containing ketones. XI. Copper (II) complexes of syn-2-picolyl phenyl and syn-2-picolyl methyl ketoximes. Inorg. Chimica Acta. 1983, 74, 279-284. (c) Holynska, M. Structural variety and magnetic properties of oxime-bridged copper(II) complexes. J. of Mol. Struct. 2015, 1098, 175-180.

${ }^{20}$ (a) Jandeleit, B.; Schaefer, D.J.; Powers, T.S.; Turner, H.W.; Weinberg, W.H. Combinatorial materials science and catalysis. Angew. Chem. Int. Ed. 1999, 38, 2494-2532. (b) Reetz, M.T. Combinatorial and evolution-based methods in the creation of enantioselective catalysts. Angew. Chem. Int. Ed. 2001, 40, 284-310. (c) Garbacia, S.; Touzani, R.; Lavastre, O. Image analysis as a quantitative screening test in combinatorial catalysis: discovery of an unexpected ruthenium-based catalyst for the sonogashira reaction. J. Comb. Chem. 2004, 6, 297-300. (d) Lavastre, O.; Bonette, F.; Gallard, L. Parallel and combinatorial approaches for synthesis of ligands. Current opinion in Chemical Biology 2004, 8, 311-318. 
${ }^{21}$ Colin, B.; Lavastre, O.; Fouquay, S.; Michaud, G.; Simon, F.; Laferte, O.; Brusson, J.M. Development of new high-throughput method to compare and to detect efficient catalysts for adhesive materials. Int. J. Adhes. Adhes. 2016, 68, 47-53

${ }^{22}$ Goldcamp, M.J.; Rosa, D.T.; Landers, N.A.; Mandel, S.M.; Krause Bauer, J.A., Baldwin M.J. Facile and Versatile Synthesis of Polydentate Metal Chelators with Both Amide and Oxime Donor Groups. Synthesis 2000, 14, 2033-2038.

${ }^{23}$ Goldcamp, M.J.; Edison, S.D.; Squires, L.N.; Rosa, D.T.; Vowels, N.K.; Coker, N.L.; Krause Bauer, J.A.; Baldwin, M.J. Structural and Spectroscopic Studies of Nickel(II) Complexes with a Library of Bis(oxime)amine-Containing Ligands. Inorg. Chem. 2003, 42, 717-728.

${ }^{24}$ Damljanovic, I.; Vukicevic, M.; Vukicevic, R.D. A simple synthesis of oximes. Monatshefte für chemie 2006, 137, 301-305.

${ }^{25}$ Buyuktas, B.S.; Aktas, O. Complexation of titanium $n$-butoxide $\mathrm{Ti}\left(\mathrm{OBu}^{\mathrm{n}}\right)_{4}$ and zirconium nbutoxide $\mathrm{Zr}\left(\mathrm{OBu}^{\mathrm{n}}\right)_{4}$ with some ligands and structural analysis of the complexes. Transition Metal Chemistry 2006, 31, 56-61.

${ }^{26}$ Baumann, S.O.; Bendova, M.; Fric, H.; Puchberger, M.; Visinescu, C.; Schubert, U. Ketoximate derivatives of titanium alkoxides and partial hydrolysis products thereof. Eur. J. Inorg. Chem. 2009, 22, 3333-3340.

27 (a) Baumann, S.O.; Puchberger, M.; Schubert, U. Oximate-substituted zirconium alkoxides. Dalton Trans. 2011, 40, 1401-1406. (b) Davidson, M.G.; Johnson, A.L.; Jones, M.D.; Lunn, M.D.; Mahon, M.F. Titanium(IV) complexes of oximes - novel binding modes. Polyhedron 2007, 26, 975-980. 